\title{
A Novel Process Using Ion Exchange Resins for the Coproduction of Ethyl and Butyl Acetates
}

\author{
Nydia Ileana Guzmán Barrera, Cécile Bories, Jérôme Peydecastaing, Caroline Sablayrolles, \\ Emeline Vedrenne, Carlos Vaca-Garcia, Sophie Thiebaud-Roux*
}

Laboratoire de Chimie Agro-industrielle (LCA), Université de Toulouse, INRA, INPT, Toulouse, France

Email: *sophie.thiebaudroux@ensiacet.fr

How to cite this paper: Guzmán Barrera, N.I., Bories, C., Peydecastaing, J., Sablayrolles, C., Vedrenne, E., Vaca-Garcia, C. and Thiebaud-Roux, S. (2018) A Novel Process Using Ion Exchange Resins for the Coproduction of Ethyl and Butyl Acetates. Green and Sustainable Chemistry, 8, 221-246. https://doi.org/10.4236/gsc.2018.83016

Received: April 7, 2018

Accepted: July 29, 2018

Published: August 1, 2018

Copyright $\odot 2018$ by authors and Scientific Research Publishing Inc. This work is licensed under the Creative Commons Attribution International License (CC BY 4.0).

http://creativecommons.org/licenses/by/4.0/

\begin{abstract}
Before proposing an innovative process for the coproduction of ethyl and butyl acetates, the individual syntheses of ethyl acetate and butyl acetate by two different routes were first studied. These syntheses involved the reaction of ethanol or $n$-butanol with acetic acid or acetic anhydride in the presence of ion exchange resins: Amberlyst 15, Amberlyst 16, Amberlyst 36 and Dowex 50WX8. Kinetic and thermodynamic studies were performed with all resins. The lowest activation energy $\left(\mathrm{E}_{\mathrm{a}}\right)$ value was obtained with Dowex 50WX8, which was identified as the best-performing resin, able to be reused at least in four runs without regeneration. The presence of water-azeotropes during the synthesis of ethyl acetate makes its purification difficult. A new strategy was adopted here, involving the use of ethanol and acetic anhydride as the starting material. In order to minimize acetic acid as co-product of this reaction, a novel two-step process for the coproduction of ethyl and butyl acetates was developed. The first step involves the production of ethyl acetate and its purification. Butyl acetate was produced in the second step: $n$-butanol was added to the mixture of acetic acid and the resin remaining after the first-step distillation. This process yields ethyl acetate and butyl acetate at high purity and shows an environmental benefit over the independent syntheses by green metrics calculation and life cycle assessment.
\end{abstract}

\section{Keywords}

Ion Exchange Resins, Esterification, Ethyl Acetate, Butyl Acetate, Coproduction, Life Cycle Assessment

\section{Introduction}

Ethyl acetate (EAc) and butyl acetate (BAc) are among the solvents most fre- 
quently used in the coating, adhesive, ink and cosmetic industries [1]. They are conventionally produced by the esterification of acetic acid $(\mathrm{AcOH})$ with excess alcohol (ethanol $(\mathrm{EtOH})$ and $n$-butanol $(\mathrm{BuOH})$, respectively) in the presence of homogeneous acid catalysts. Strong liquid mineral acids, such as sulfuric acid, p-toluenesulfonic acid (PTSA) and hydrochloric acid, are the most effective catalysts for achieving high esterification yields [2] [3] [4]. However, these processes require the use of alkaline salt solutions for catalyst neutralization, resulting in the generation of aqueous waste [5].

The use of ion-exchange resins bearing sulfonic acid $\left(-\mathrm{SO}_{3} \mathrm{H}\right)$ groups as heterogeneous catalysts in esterification reactions is well documented [6]-[12]. These resins generally give results similar to those obtained with homogeneous acid catalysts [13]. The use of a heterogeneous ion exchange resin as a catalyst is advantageous in a number of ways. In particular, by contrast to processes involving the use of homogeneous acid catalysts, there is no need to neutralize the medium. This limits waste production [14]. Side reactions are also limited, resulting in higher reaction yield and higher product purity [15]. The resin is easy to remove from the reaction medium by filtration or decantation [16] [17]. The recovered resin can be reused without regeneration, but can also be regenerated for further use [18] [19] [20] [21].

Esterification reactions are known to be equilibrium-limited. The equilibrium is often shifted by adding an excess of one of the reactants or by removing one of the products (i.e. water) during the reaction (Le Chatelier's principle). However, the presence of azeotropes makes purification more difficult, due to the need for energy-intensive processes. Ethyl acetate is generally purified by rectification, in several distillation steps. However, each step reduces the yield and additional recycling is required. It can also be extracted through extractive distillation with an agent containing DMSO [22], polyethylene glycol or dipropylene glycol [23] or using ionic liquids (ILs) [24] [25]. More recently, pressure-swing distillation has been explored [26] [27] [28]. Reactive distillation (RD) has also been studied as a method for producing this ester, to avoid azeotropic limitation and to increase yield and purity [29]-[35].

In this study, a novel coproduction process for ethyl acetate and butyl acetate was studied, with the aim of rendering the syntheses of these two molecules greener and easier to perform in terms of ester purification. Firstly, we studied the individual syntheses of ethyl acetate and butyl acetate by two different routes, using acetic acid or acetic anhydride with the corresponding alcohols (ethanol or n-butanol). Four ion exchange resins were compared: Amberlyst 15 (A15), Amberlyst 16 (A16), Amberlyst 36 (A36) and Dowex 50WX8 (D50). Kinetic studies were performed for all reactions, for both syntheses and routes, to ensure the selection of the best resin for the coproduction process. The recycling of the most effective resin was also evaluated by studying its activity over several production cycles.

The coproduction of ethyl and butyl acetates has already been reported by 
Tian and coworkers [34] [36]. They studied the feasibility of coproduction with the Aspen Plus ${ }^{\circledR}$ simulation tool and then checked the simulated model experimentally. However, the process described requires two reactive distillation columns: one for the synthesis of ethyl acetate and the other for butyl acetate.

The coproduction process proposed here consists of two steps. The first consists of the production of ethyl acetate from ethanol and acetic anhydride in the presence of the ion exchange resin selected in preliminary studies of the catalytic effects of resins on the separate syntheses of the two acetates. In this synthetic route, acetic acid is produced, and water formation is limited, making it possible to purify ethyl acetate by simple distillation. In the second step, n-butanol is added to the residual mixture of acetic acid and resin remaining after distillation to purify the product of the first esterification. Finally, the butyl acetate obtained is purified by distilling the heteroazeotrope formed after the addition of a selective entrainer facilitating the liquid/liquid separation of water in the decanter.

\section{Experimental}

\subsection{Chemicals}

Ethanol, n-butanol, acetic anhydride, acetic acid, cyclohexane and methyl isobutyl ketone, all analytical grade, were purchased from Sigma Aldrich Co. (France). Sodium chloride was also obtained from Sigma Aldrich Co. (France).

\subsection{Catalyst}

Heterogeneous ion exchange resins: Amberlyst 15, Amberlyst 16, Amberlyst 36 and Dowex 50WX8 were supplied by Sigma Aldrich Co. (France). They were used as catalysts for the esterification reactions, after washing in water, filtration and drying to constant weight in an oven at $50^{\circ} \mathrm{C}$ to eliminate any moisture.

\subsection{Synthesis of Ethyl Acetate (EAc): Selection of Catalyst and Reaction Conditions}

In a typical run, a mixture of $0.20 \mathrm{~g}$ ethanol $(4.4 \mathrm{mmol}, 1$ equiv.) and $0.26 \mathrm{~g}$ acetic acid ( $4.4 \mathrm{mmol}, 1$ equiv.) was stirred at $80^{\circ} \mathrm{C}$ in the presence of the resin $(5 \%$ $\mathrm{w} / \mathrm{w}$ relative to ethanol). The reaction was also carried out with $0.25 \mathrm{~g}$ ethanol (5.4 mmol, 1 equiv.) and $0.28 \mathrm{~g}$ acetic anhydride ( $2.7 \mathrm{mmol}, 0.5$ equiv.) or $0.56 \mathrm{~g}$ acetic anhydride ( $5.5 \mathrm{mmol}, 1$ equiv.). The ethyl acetate obtained was then purified by simple distillation.

\subsection{Synthesis of Butyl Acetate (BAc)}

Butyl acetate was produced in a $2 \mathrm{~L}$ jacketed glass reactor equipped with a Dean-Stark apparatus. A solution of $800 \mathrm{~g} n$-butanol (10.8 mol, 1 equiv.), $648 \mathrm{~g}$ acetic acid (10.8 mol, 1 equiv.) and $80 \mathrm{~mL}$ cyclohexane (as an entrainer, to remove water from the reaction medium) was stirred in the presence of the resin $\left(5 \% \mathrm{w} / \mathrm{w}\right.$ relative to butanol) at $105^{\circ} \mathrm{C}$ for $4 \mathrm{~h}$. The cyclohexane was then removed from the reaction mixture by distillation. The butyl acetate was recovered 
by filtration of the resin.

\subsection{Coproduction of Ethyl Acetate and Butyl Acetate}

A mixture of $400 \mathrm{~g}$ ethanol ( $8.7 \mathrm{~mol}, 1$ equiv.) and $889 \mathrm{~g}$ acetic anhydride (8.7 mol, 1 equiv.) was stirred in the presence of the resin $(5 \% \mathrm{w} / \mathrm{w}$ relative to ethanol) in a $2 \mathrm{~L}$ jacketed glass reactor at room temperature for $4 \mathrm{~h}$. The ethyl acetate formed was then distilled off from the reaction medium. We then added $400 \mathrm{~g}$ $n$-butanol (5.4 mol, 1 equiv.) and $45 \mathrm{~mL}$ cyclohexane (5\% v/v relative to the reaction mixture) to the reactor containing the remaining acetic acid and resin mixture. The reactor was equipped with a Dean-Stark apparatus (to remove water from the reaction medium). The resulting medium was stirred at $105^{\circ} \mathrm{C}$ for 4 h. At the end of the reaction, cyclohexane was removed by simple distillation and the butyl acetate was recovered after catalyst filtration.

\subsection{Analysis Methods}

The reaction products were analyzed with a gas chromatograph (VARIAN 3600) equipped with a flame ionization detector. A DB-624 column (AGILENT, 0.25 $\mathrm{mm} \times 30 \mathrm{~m}, \mathrm{df}=1.4 \mu \mathrm{m}$ ) was used for the analyses. The oven temperature was maintained at $50^{\circ} \mathrm{C}$ for $2 \mathrm{~min}$, then gradually increased to $100^{\circ} \mathrm{C}$ at a rate of $5^{\circ} \mathrm{C} / \mathrm{min}$ and then to $190^{\circ} \mathrm{C}$ at a rate of $25^{\circ} \mathrm{C} / \mathrm{min}$. The temperature of the detector and the injector was fixed at $300^{\circ} \mathrm{C}$. The injection volume of samples was 1 $\mu \mathrm{L}$, with a 1:100 split. Methyl isobutyl ketone (MIBK) was used as the internal standard. Water content was determined by Karl Fisher titration (SCHOTT Titroline)

\subsection{Statistical Analyses}

Statistical analyses were performed with Minitab 16 software. Data were analyzed by analysis of variance (ANOVA) and with Tukey's test, with an alpha risk of $0.05(\mathrm{p}<0.05)$

\subsection{Life Cycle Assessment}

The Life Cycle Assessment was performed using the ISO 14040 [37] and 14044 [38] standards. The LCA analyses were "cradle to gate" in order to evaluate the impacts related to the syntheses. The production of $1 \mathrm{~kg}$ of BAc was chosen as functional unit. Then, it was calculated that $1.235 \mathrm{~kg}$ of EAc (functional unit for EAc) needed to be synthesized for producing the amount of acetic acid (0.749 $\mathrm{kg}$ ) necessary for the synthesis of $1 \mathrm{~kg}$ of BAc.

All the data for the Life Cycle Inventory were collected from the experimental results at laboratory scale. The emissions and extractions data were obtained from the Ecoinvent 3.1 database. The environmental impacts were analyzed through a derivative of the ILCD 20111.05 method. Indicators of resources depletion of this method were replaced by water depletion and energy consumption indicator, based on the Cumulative Energy Demand method, because of the 
lack of confidence. 17 midpoint impact categories were studied. The inventory and the impact calculations were done on SigmaPro 8.1.1.

\section{Results and Discussion}

\subsection{Synthesis of Ethyl Acetate Starting from Ethanol and Acetic Acid}

The main industrial process for ethyl acetate (EAc) production involves the esterification of acetic acid $(\mathrm{AcOH})$ with ethanol $(\mathrm{EtOH})$ in the presence of a homogeneous catalyst, generally sulfuric acid. We decided to circumvent the problems relating to the use of homogeneous catalysts, such waste production and separation, and to use a greener approach. We therefore replaced the acid catalyst with a heterogeneous ion exchange resin.

Experiments were carried out with different ion exchange resins, to evaluate the efficiency of conversion of ethanol and n-butanol into ethyl acetate and n-butyl acetate (BAc), respectively. Four ion exchange resins were used: Amberlyst 15 (A15), Amberlyst 16 (A16), Amberlyst 36 (A36) and Dowex 50WX8 (D50). The beads of these resins consist of styrene-divinylbenzene copolymers. A15, A16 and A36 are macroporous resins with multichannel structures, whereas Dowex 50WX8 is a gel resin. The properties of these resins are presented in Table 1.

The capacity of each resin was determined in terms of exchangeable counterions per unit dry weight, with a $0.2 \mathrm{M}$ solution of $\mathrm{NaOH}$. Ion exchange capacity is expressed in milliequivalents per gram of resin. The highest resin capacity was obtained with Amberlyst 16 (Table 1). The other resins had similar capacities.

We therefore began by studying the synthesis of ethyl acetate starting from ethanol and acetic acid in a 1:1 molar ratio (Equation (1)), replacing the homogeneous catalyst with each of the ion exchange resins described in Table 1.

$$
\mathrm{CH}_{3} \mathrm{COOH}+\mathrm{CH}_{3} \mathrm{CH}_{2} \mathrm{OH} \rightleftharpoons \mathrm{CH}_{3} \mathrm{COOCH}_{2} \mathrm{CH}_{3}+\mathrm{H}_{2} \mathrm{O}
$$

The reactions were carried out at $80^{\circ} \mathrm{C}$ and the final composition of the reaction medium was analyzed by gas chromatography. The changes in the ethanol,

Table 1. Characteristics of the resins used for the synthesis of ethyl and butyl acetates.

\begin{tabular}{|c|c|c|c|c|c|c|c|c|}
\hline Catalyst & Physical form & $\begin{array}{l}\text { Concentration of } \\
\text { acid sites }\end{array}$ & $\begin{array}{c}\text { Shipping } \\
\text { weight }(\mathrm{g} / \mathrm{L})\end{array}$ & Fine content & Coarse beads & $\begin{array}{c}\text { Surface } \\
\text { area }\left(\mathrm{m}^{2} / \mathrm{g}\right)\end{array}$ & $\begin{array}{c}\text { Mean pore } \\
\text { diameter }\end{array}$ & $\begin{array}{c}\text { Ion exchange } \\
\text { capacity }(\mathrm{meq} / \mathrm{g})^{\mathrm{a}}\end{array}$ \\
\hline Amberlyst 15 & Opaque beads & $\begin{array}{c}\geq 1.7 \mathrm{eq} / \mathrm{L} \\
\geq 4.7 \mathrm{eq} / \mathrm{kg}\end{array}$ & 610 & $\begin{array}{l}<0.300 \mathrm{~mm}: \\
0.5 \% \max \end{array}$ & $\begin{array}{c}>1.18 \mathrm{~mm}: 5 \% \\
\max \end{array}$ & 53 & $300 \AA$ & 4.9 \\
\hline Amberlyst 16 & Opaque beads & $\begin{array}{c}\geq 1.7 \mathrm{eq} / \mathrm{L} \\
\geq 4.7 \mathrm{eq} / \mathrm{kg}\end{array}$ & 780 & $\begin{array}{c}<0.355 \mathrm{~mm}: \\
1 \% \max \end{array}$ & $\begin{array}{c}>1.18 \mathrm{~mm}: 5 \% \\
\max \end{array}$ & 52 & $300 \AA$ & 6.1 \\
\hline Amberlyst 36 & Opaque beads & $\begin{array}{c}\geq 1.95 \mathrm{eq} / \mathrm{L} \geq 5.4 \\
\mathrm{eq} / \mathrm{kg}\end{array}$ & 800 & $\begin{array}{c}<0.425 \mathrm{~mm}: \\
0.5 \% \max \end{array}$ & $\begin{array}{c}>1.18 \mathrm{~mm}: 4 \% \\
\max \end{array}$ & 33 & $240 \AA$ & 4.9 \\
\hline $\begin{array}{c}\text { Dowex 50WX8 } \\
200-400\end{array}$ & $\begin{array}{c}\text { Crystalline } \\
\text { powder or powder }\end{array}$ & $\geq 1.7 \mathrm{eq} / \mathrm{L}$ & 802 & NA & NA & NA & $10-20 \AA$ & 4.8 \\
\hline
\end{tabular}

a. Ion exchange capacity of resins determined in this work. Standard deviation $=0.2 \mathrm{meq} / \mathrm{g}$. 

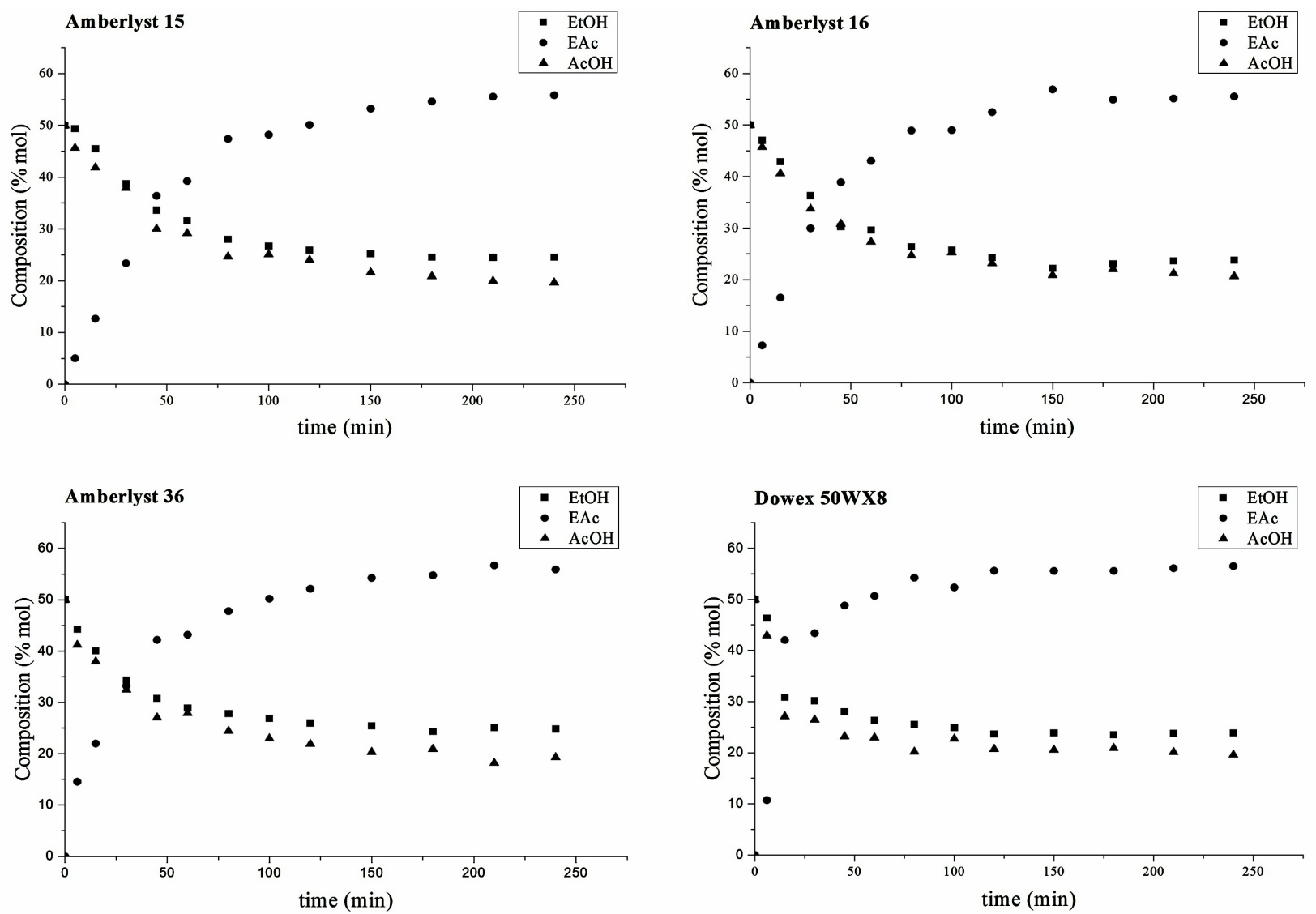

Figure 1. Kinetic study of the synthesis of ethyl acetate from ethanol and acetic acid (molar ratio: $1 / 1$ ) at $80^{\circ} \mathrm{C}$, in the presence of the various ion exchange resins: A15, A16, A36 and D50 (catalyst loading: 5\% w/w relative to ethanol). 
The low ethanol conversion can be attributed to the formation of water, which shifts the equilibrium toward the reactants, thereby limiting ethyl acetate production.

\subsection{Effect of Reaction Temperature}

The effect of temperature on ethanol conversion was assessed by setting the temperature to $90,80,65,50$ and $40^{\circ} \mathrm{C}$. The ethanol conversion plots as a function of reaction temperature are presented in Figure 2. Similar profiles were obtained with all the resins tested (data shown only for Dowex 50WX8). The reaction rate increased with temperature. For the esterification of ethanol and acetic acid, reaction equilibrium was reached after 60 minutes at $90^{\circ} \mathrm{C}$, but after $5 \mathrm{~h}$ at $50^{\circ} \mathrm{C}$.

The effect of temperature on the reaction rate was investigated by setting the

Table 2. Comparison of the various resins in terms of their ethanol conversion and ethyl acetate yields, for reactions starting from ethanol and acetic acid (molar ratio: 1/1).

\begin{tabular}{ccccccc}
\hline \multirow{2}{*}{$\begin{array}{c}\text { Ion exchange } \\
\text { resins }\end{array}$} & \multirow{2}{*}{$\begin{array}{c}\text { Conversion of } \\
\text { ethanol (\%) }\end{array}$} & $\begin{array}{c}\text { Yield of EAc } \\
\text { (\%) }\end{array}$ & \multicolumn{3}{c}{ Composition of reaction media (\%mol) } \\
\cline { 5 - 7 } Amberlyst 15 & 71 & 69 & 17 & 14 & 35 & 34 \\
Amberlyst 16 & 71 & 69 & 16 & 14 & 34 & 36 \\
Amberlyst 36 & 71 & 69 & 16 & 14 & 35 & 35 \\
$\begin{array}{c}\text { Dowex 50WX8 } \\
200-400\end{array}$ & 70 & 68 & 16 & 15 & 34 & 35 \\
\hline
\end{tabular}

Conditions: resin loading $5 \% \mathrm{w} / \mathrm{w}$ relative to $\mathrm{EtOH}, 80^{\circ} \mathrm{C}, 4 \mathrm{~h}$, a. Determined by Karl Fisher titration. SD: \pm 2 .

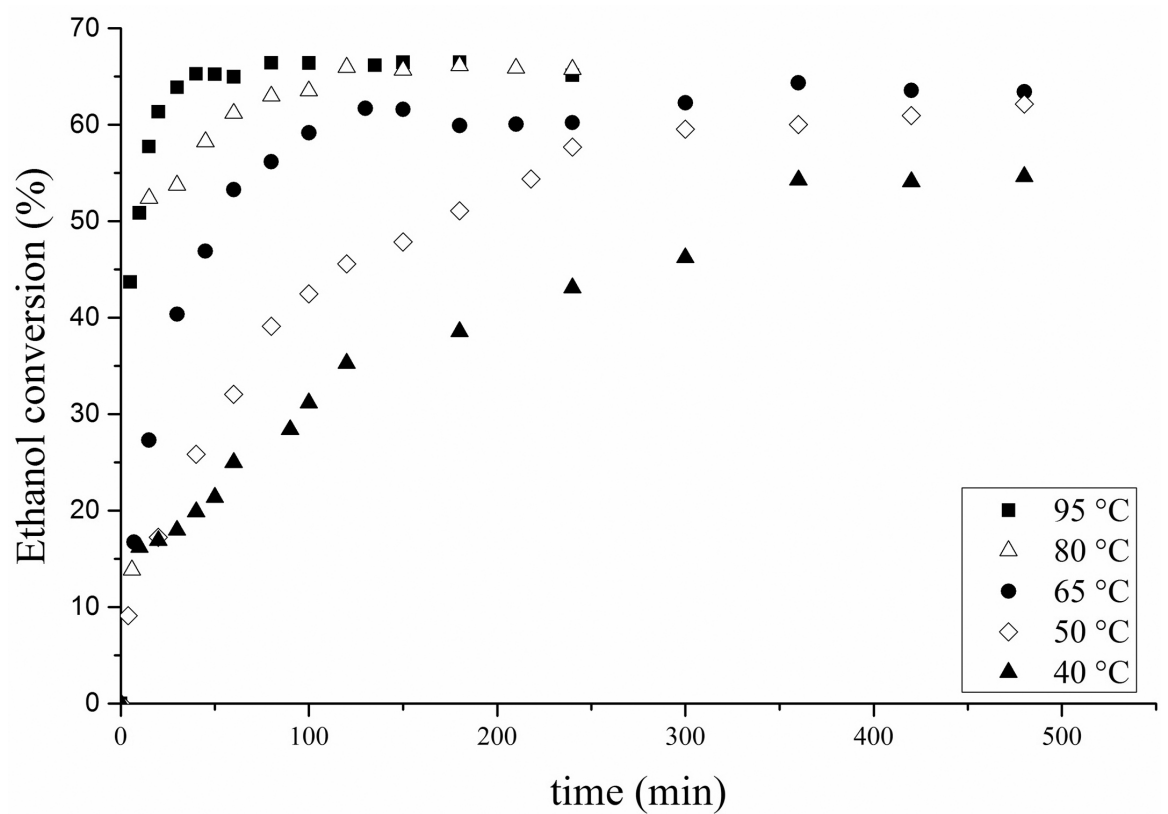

Figure 2. Effect of temperature on ethanol conversion with Dowex 50WX8 as the catalyst. Reaction starting from ethanol and acetic acid (1/1). Catalyst loading: 5\% w/w relative to EtOH. 


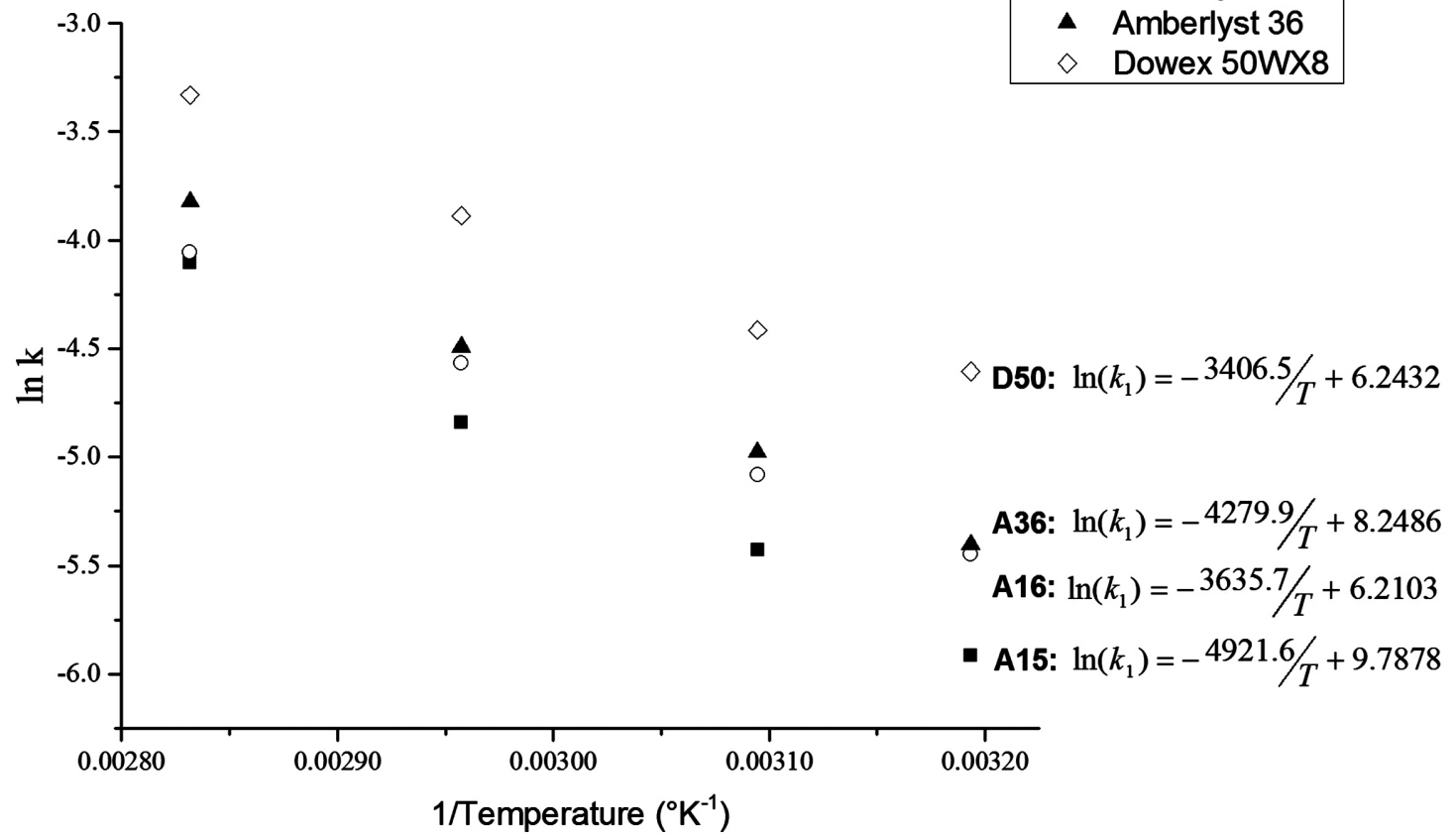

Figure 3. Activation energy determination, natural logarithm of the equilibrium constants as a function of the inverse of temperature. 


\subsection{Synthesis of Ethyl Acetate Starting from Ethanol and Acetic Anhydride}

We tried to increase reaction yield and to shift the equilibrium towards ester formation, by testing the resins in another synthetic route, starting from ethanol and acetic anhydride (Equation (2)).

$$
\left(\mathrm{CH}_{3} \mathrm{CO}\right)_{2} \mathrm{O}+2 \mathrm{CH}_{3} \mathrm{CH}_{2} \mathrm{OH} \rightleftharpoons 2 \mathrm{CH}_{3} \mathrm{COOCH}_{2} \mathrm{CH}_{3}+\mathrm{H}_{2} \mathrm{O}
$$

There are fewer published descriptions of the synthesis of esters from an anhydride. Kolena et al. patented a method for synthesizing ethyl acetate by reactive distillation, using a mixture of acetic acid and acetic anhydride [44]. The synthesis of methyl acetate by this route has also been reported [45] [46]. This reaction has the advantage of decreasing water formation due to the reaction stoichiometry and partial consumption for the hydrolysis of acetic anhydride into acetic acid.

The esterification reaction starting from ethanol and acetic anhydride (Equation (2)) is best summarized by the following steps:

$$
\begin{gathered}
\left(\mathrm{CH}_{3} \mathrm{CO}\right)_{2} \mathrm{O}+\mathrm{CH}_{3} \mathrm{CH}_{2} \mathrm{OH} \rightleftharpoons \mathrm{CH}_{3} \mathrm{COOCH}_{2} \mathrm{CH}_{3}+\mathrm{CH}_{3} \mathrm{COOH} \\
\mathrm{CH}_{3} \mathrm{CH}_{2} \mathrm{OH}+\mathrm{CH}_{3} \mathrm{CH}_{2} \mathrm{OH} \rightleftharpoons \mathrm{CH}_{3} \mathrm{COOCH}_{2} \mathrm{CH}_{3}+\mathrm{H}_{2} \mathrm{O} \\
\left(\mathrm{CH}_{3} \mathrm{CO}\right)_{2} \mathrm{O}+\mathrm{H}_{2} \mathrm{O} \rightleftharpoons \mathrm{CH}_{3} \mathrm{COOH}
\end{gathered}
$$

We checked our findings suggesting a greater efficiency of Dowex 50WX8, by testing all the resins for catalysis of the esterification of acetic anhydride with ethanol. The reactions were carried out with an ethanol:acetic anhydride molar ratio of $2: 1$, at $80^{\circ} \mathrm{C}$, with $\mathrm{A} 15, \mathrm{~A} 16, \mathrm{~A} 36$ or Dowex $50 \mathrm{WX} 8$ as the catalyst. The course of the reactions was followed over a period of $180 \mathrm{~min}$ (Figure 4).

The equilibrium of the reaction was reached more rapidly if acetic anhydride was used in place of acetic acid. For the macroporous resins A15, A16 and A36, equilibrium was reached after $90 \mathrm{~min}$ with acetic anhydride, and $180 \mathrm{~min}$ with acetic acid (Figure 4). The reaction performed with acetic anhydride in the presence of Dowex 50WX8 was also slightly faster, reaching equilibrium at 60 min, versus 90 min with acetic acid (Figure 1 vs Figure 4).

The ethanol conversion and the yield of ethyl acetate were determined by GC and similar values were obtained for all four resins at equilibrium. Higher conversion and yields were obtained for reactions starting from acetic anhydride rather than acetic acid (10\% increase in conversion; Table 2 vs Table 3$)$. This may be due to the smaller amount of water in the medium (from 34 to $20 \% \mathrm{~mol}$, with acetic acid and acetic anhydride, respectively) due to its consumption in the hydrolysis of acetic anhydride into acetic acid, as described in Equation (5), shifting the equilibrium to the right.

Based on these kinetic results, Dowex 50WX8 was considered to be the most efficient acidic ion exchange resin for the rapid production of high yields of ethyl acetate. Higher ethanol conversion and reaction yields were also obtained for the reaction starting from ethanol and acetic anhydride. We therefore decided to use 

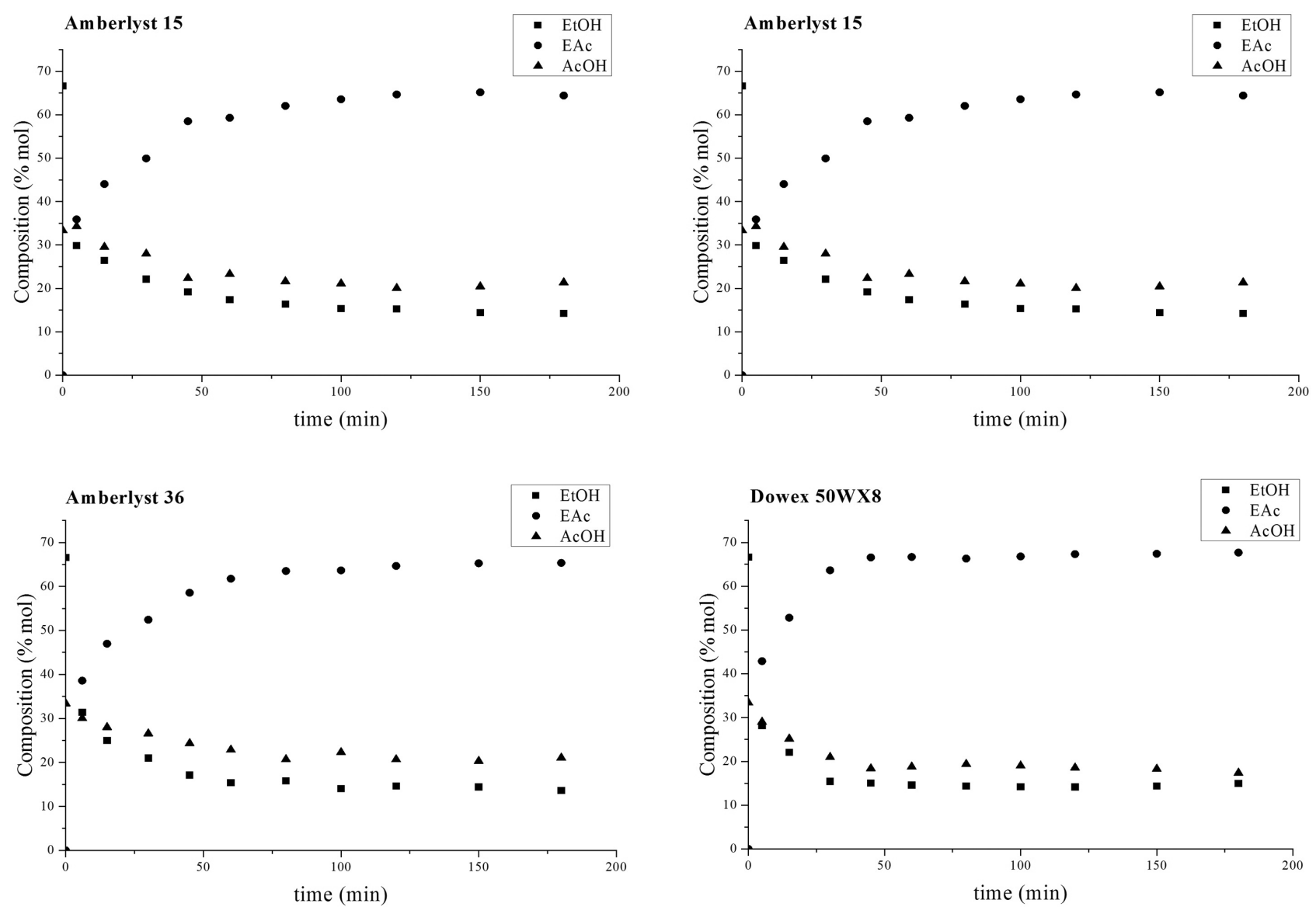

Figure 4. Kinetic study of the synthesis of ethyl acetate from ethanol and acetic anhydride (molar ratio: $2 / 1$ ) at $80^{\circ} \mathrm{C}$, in the presence of different ion exchange resins: A15, A16, A36 or D50 (catalyst loading: 5\% w/w relative to ethanol).

Table 3. Comparison of the different ion-exchange resins in terms of their ethanol conversion and ethyl acetate yields, for the reaction starting from ethanol and acetic anhydride $(2 / 1)$.

\begin{tabular}{ccccccc}
\hline \multirow{2}{*}{ Ion exchange resins } & \multirow{2}{*}{$\begin{array}{c}\text { Conversion of } \\
\text { ethanol (\%) }\end{array}$} & $\begin{array}{c}\text { Yield of EAc } \\
(\%)\end{array}$ & \multicolumn{4}{c}{ Composition of reaction media (\%mol) } \\
\cline { 5 - 7 } & 81 & 78 & 15 & 13 & 53 & 19 \\
\hline Amberlyst 15 & 80 & 83 & 15 & 13 & 53 & 18 \\
Amberlyst 16 & 80 & 80 & 15 & 13 & 54 & 18 \\
Amberlyst 36 & 79 & 83 & 15 & 14 & 54 & 17 \\
Dowex 50WX8 200 - 400 & 79 & &
\end{tabular}

Conditions: resin loading $5 \%$ w/w relative to $\mathrm{EtOH}, 80^{\circ} \mathrm{C}, 4 \mathrm{~h}$, a. Determined by Karl Fisher titration. SD: \pm 2 .

these reactants as the starting materials, with Dowex 50WX8 as the catalyst, in subsequent studies.

\subsection{Evaluation of Dowex 50WX8: Catalyst Loading and Reusability}

The influence of catalyst loading on the ethyl acetate yield obtained at equilibrium was evaluated with a 2:1 molar ratio of ethanol:acetic anhydride. The reaction was carried out at $80^{\circ} \mathrm{C}$ for $4 \mathrm{~h}$, with a catalyst loading of $2.5 \%, 5 \%$ and $10 \%$ 
dry weight relative to the weight of ethanol. Ethyl acetate yield increased with resin loading (Figure 5). Nevertheless, for confirmation of the positive effect of the increase in catalyst loading on ethyl acetate yield, an analysis of variance (ANOVA) was performed. Ethyl acetate yield differed significantly between resin loadings ( $\alpha=0.05, \mathrm{p}=0.041$ ). Nevertheless, a Tukey test showed that there was no significant difference between catalyst loadings of $5 \%$ and $10 \%$. We therefore considered a catalyst loading of $5 \%$ to be sufficient to obtain the maximum yield of ethyl acetate.

The reusability of Dowex 50WX8 was then assessed by evaluating ethyl acetate yield after several recycling runs (Figure 6). The test was performed with the same catalyst for four consecutive runs, under the same conditions; the catalyst was filtered and washed with water between runs. The analysis of variance (ANOVA) showed that there was no significant difference in ethyl acetate yield between the runs on reused resin $(\alpha=0.05, p=0.073)$. The catalyst is thus reusable and resin reactivation is not required, at least in these conditions.

\subsection{Purification of Ethyl Acetate}

In the ethyl acetate reaction system, there are three binary azeotropes and one ternary azeotrope. As the boiling point of the pure components (ethyl acetate $77.2^{\circ} \mathrm{C}$, ethanol $78.3^{\circ} \mathrm{C}$, water $100^{\circ} \mathrm{C}$, acetic acid $118^{\circ} \mathrm{C}$ ) and the azeotropes they form are very similar, it is difficult to achieve efficient purification by distillation. The composition and boiling points of the azeotropes are shown in Table 4.

The use of extractive methods for ethyl acetate purification is also limited because this compound forms azeotropes with conventional solvents used for water removal, such as benzene $\left(\mathrm{bp}=102.45^{\circ} \mathrm{C}\right)$, cyclohexene $\left(\mathrm{bp}=100.87^{\circ} \mathrm{C}\right)$, cyclohexane $\left(b p=102.45^{\circ} \mathrm{C}\right), 1$-hexene $\left(b p=91.47^{\circ} \mathrm{C}\right)$ and hexane $(b p=$

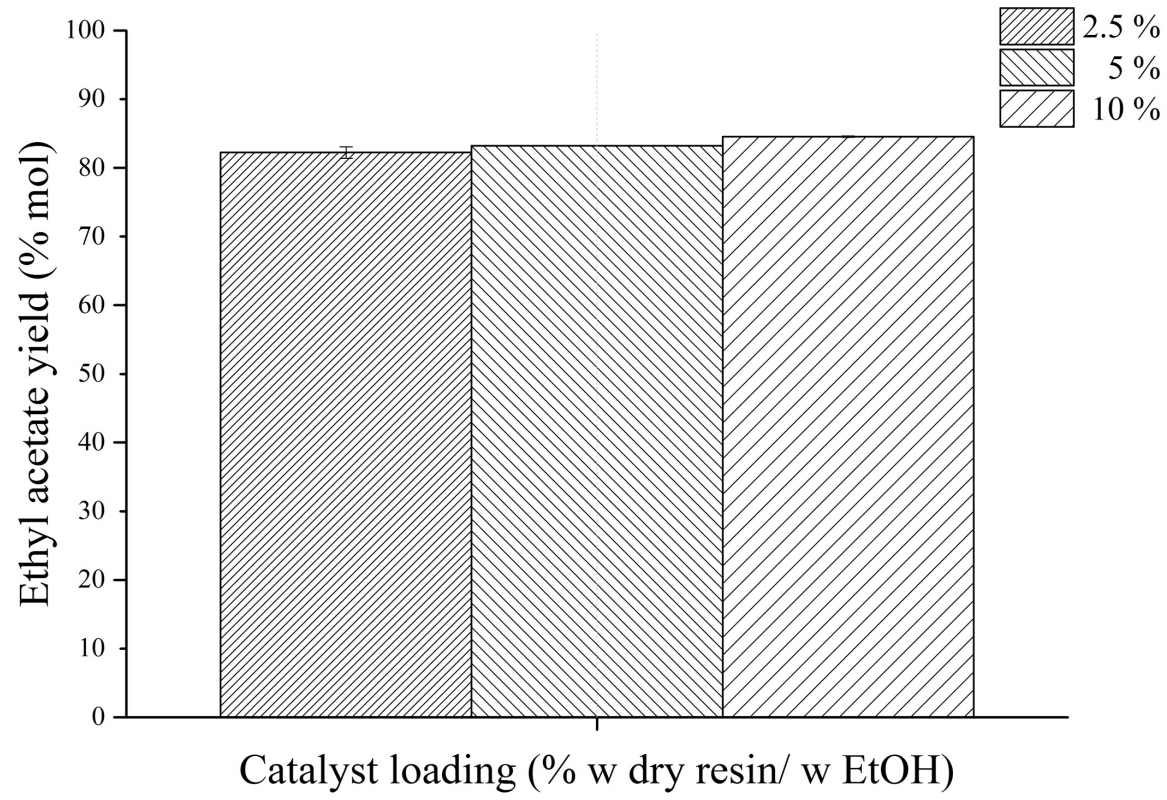

Figure 5. Evaluation of the effect of catalyst loading on EAc yield 


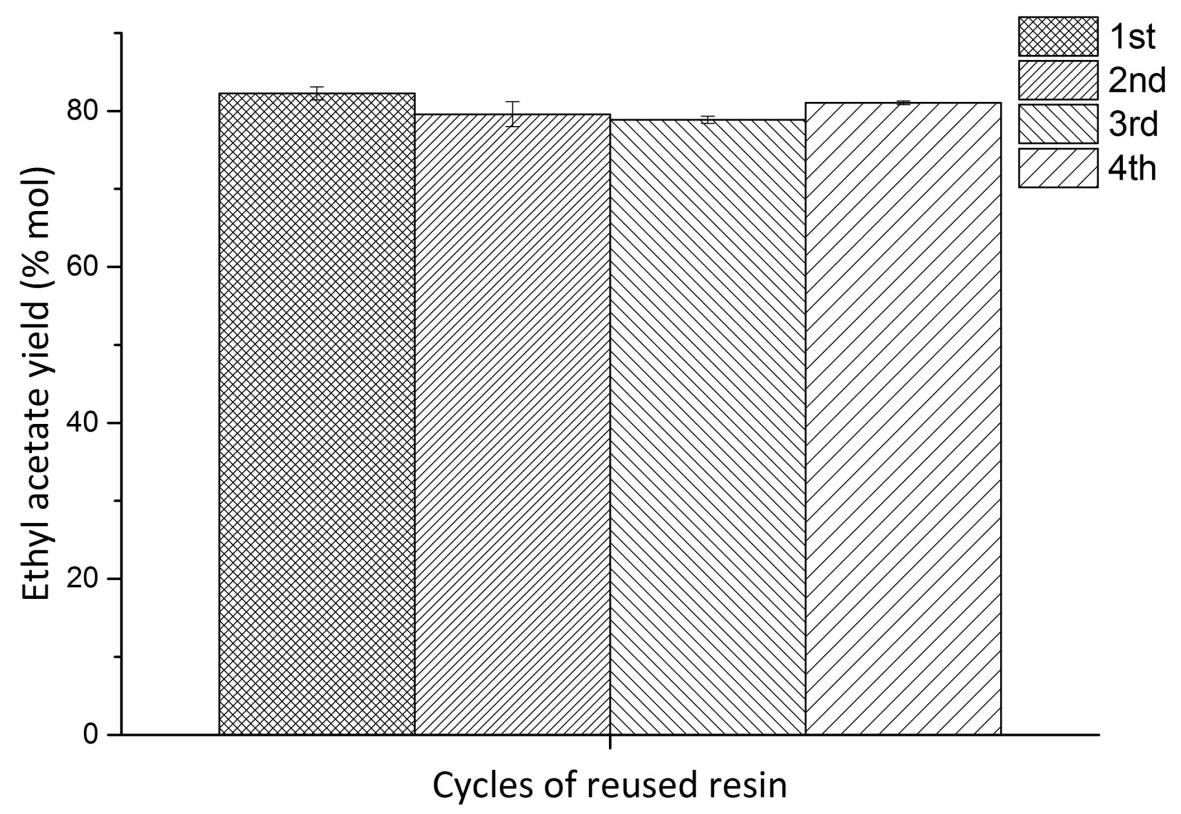

Figure 6. Effect of the reused resin on EAc yield

Table 4. Boiling points and molar fractions of the various azeotropes in the ethyl acetate system [47].

\begin{tabular}{ccccc}
\hline \multirow{2}{*}{ Azeotropes } & Boiling Point $\left({ }^{\circ} \mathrm{C}\right)$ & \multicolumn{3}{c}{ Molar fractions } \\
\cline { 3 - 5 } & & EtOH & EAc & $\mathrm{H}_{2} \mathrm{O}$ \\
\hline $\mathrm{EtOH} / \mathrm{EAc} / \mathrm{H}_{2} \mathrm{O}$ & 70.09 & 0.1069 & 0.6073 & 0.2858 \\
$\mathrm{EAc} / \mathrm{H}_{2} \mathrm{O}$ & 70.37 & - & 0.6869 & 0.3131 \\
$\mathrm{EtOH} / \mathrm{EAc}$ & 71.81 & 0.4572 & 0.5428 & - \\
$\mathrm{EtOH} / \mathrm{H}_{2} \mathrm{O}$ & 78.18 & 0.9016 & - & 0.0984 \\
\hline
\end{tabular}

\section{$\left.101.32^{\circ} \mathrm{C}\right)[48]$.}

The yield and purity of ethyl acetate (limitation of water formation) can be improved by reactive distillation (RD), to shift the chemical equilibrium and overcome azeotropic limitations [30] [49] [50]. Pervaporation (PV) has been proposed for the separation of azeotropes or the dehydration of organic compounds [31] [51] [52]. Hybrid processes, combining pervaporation with other separation techniques, for example, have also been described [31] [53] [54], but these techniques involve a complex analysis of the configuration of the columns and require special equipment. We therefore developed an alternative strategy for improving yield and facilitating ethyl acetate purification with conventional laboratory equipment.

\subsection{Synthesis of Butyl Acetate Starting From $n$-Butanol and Acetic Acid}

After studying the synthesis of ethyl acetate, we decided to evaluate Dowex 50WX8 as a catalyst for the production of butyl acetate (Bac). The synthesis of butyl acetate starting from a 1/1 molar ratio of $n$-butanol and acetic acid (Equa- 
tion (6)) was first studied, with each of the four ion exchange resins tested for ethyl acetate synthesis as the catalyst (A15, A16, A36 and D50).

$$
\mathrm{CH}_{3}\left(\mathrm{CH}_{2}\right)_{3} \mathrm{OH}+\mathrm{CH}_{3} \mathrm{COOH} \rightleftharpoons \mathrm{CH}_{3} \mathrm{COO}\left(\mathrm{CH}_{2}\right)_{3} \mathrm{CH}_{3}+\mathrm{H}_{2} \mathrm{O}
$$

The reactions were performed at $100^{\circ} \mathrm{C}$, and changes in the composition of the reaction medium were followed for $4 \mathrm{~h}$ (Figure 7).

Equilibrium was reached after about 50 minutes with Dowex 50WX8. A similar profile was obtained with A16, whereas it took 100 minutes to reach equilibrium with $\mathrm{A} 15$ and $\mathrm{A} 36$.

The $n$-butanol conversion and the yield in n-butyl acetate were determined at equilibrium, by GC analyses (Table 5).

The $n$-butanol conversion and the yield of BAc were similar for all four resins. As for ethyl acetate, the low conversion was attributed to the formation of water, shifting the equilibrium towards the reactant side.

\subsection{Effect of Reaction Temperature}

The effect of temperature on the conversion of $n$-butanol and the esterification of butanol and acetic acid was also studied, by setting the temperature at $100^{\circ} \mathrm{C}$, $80^{\circ} \mathrm{C}, 70^{\circ} \mathrm{C}, 60^{\circ} \mathrm{C}$ and $50^{\circ} \mathrm{C}$. Butanol conversion was plotted as a function of
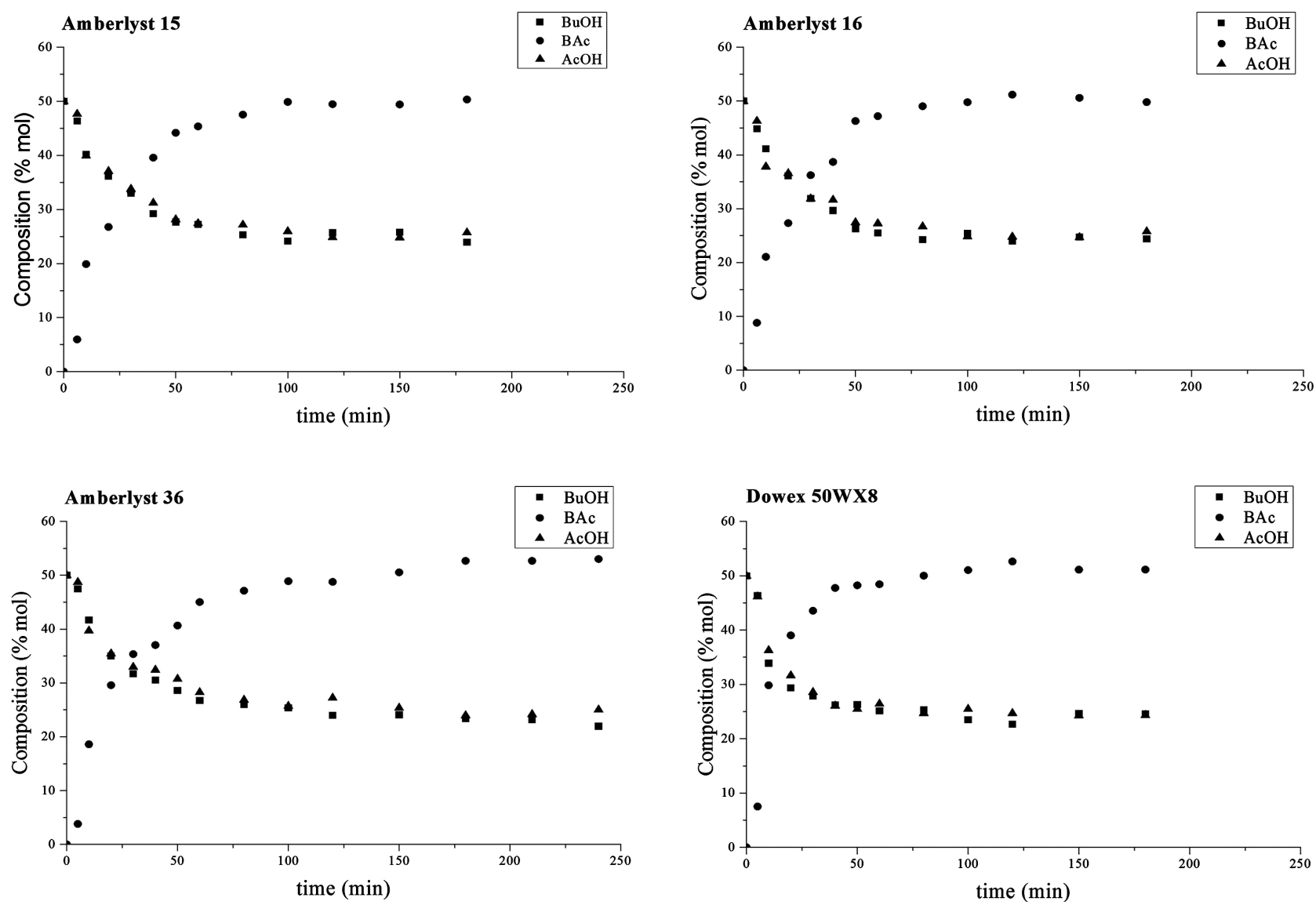

Figure 7. Kinetic study of the synthesis of butyl acetate from $n$-butanol and acetic acid (molar ratio: $1 / 1$ ) at $100^{\circ} \mathrm{C}$ in the presence of different ion exchange resins: A15, A16, A36 and D50 (catalyst loading: 5\% w/w relative to butanol). 
Table 5. Comparison of the various ion exchange resins in terms of $n$-butanol conversion and butyl acetate yield, for reactions starting from $n$-butanol and acetic acid (1:1)

\begin{tabular}{ccccccc}
\hline \multirow{2}{*}{ Ion exchange resins } & \multirow{2}{*}{$\begin{array}{c}\text { Butanol } \\
\text { conversion (\%) }\end{array}$} & $\begin{array}{c}\text { Yield of BAc } \\
(\%)\end{array}$ & \multicolumn{3}{c}{ Composition of reaction media (\%mol) } \\
\cline { 5 - 8 } & 68 & 74 & 17 & 16 & 38 & 29 \\
\hline Amberlyst 15 & 71 & 61 & 17 & 16 & 35 & 32 \\
Amberlyst 16 & 72 & 68 & 18 & 16 & 37 & 29 \\
Amberlyst 36 & 71 & 66 & 17 & 16 & 36 & 31 \\
\hline
\end{tabular}

Conditions: resin loading $5 \% \mathrm{w} / \mathrm{w} \mathrm{BuOH}, 100^{\circ} \mathrm{C}, 4 \mathrm{~h}$. a: determined by Karl Fisher titration. Standard deviation: $\pm 2 \%$.

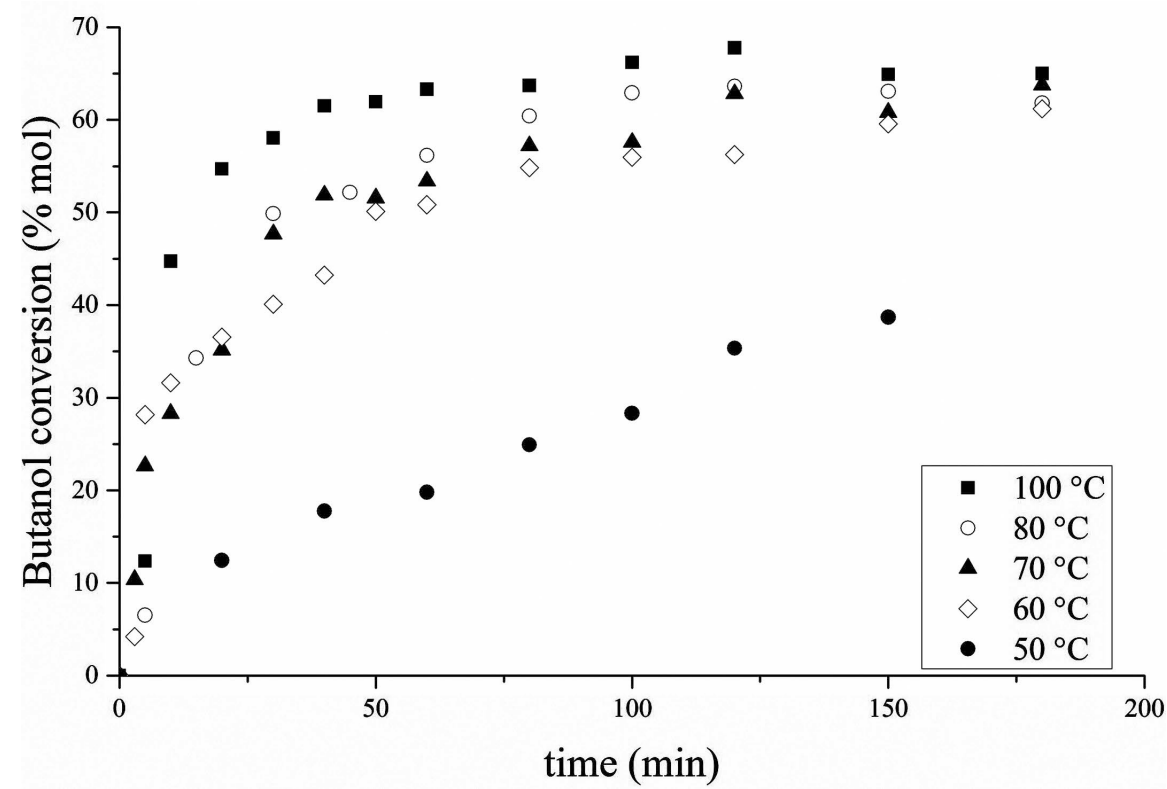

Figure 8. Effect of temperature on the conversion of $n$-butanol.

temperature (Figure 8). The reaction rate increased with increasing temperature, with the fastest conversion of butanol observed at $100^{\circ} \mathrm{C}$. Equilibrium was reached after about $80-100 \mathrm{~min}$ at this temperature, whereas it took 180 minutes at $60^{\circ} \mathrm{C}$.

The activation energy ( $\mathrm{Ea})$ was determined from the Arrhenius plot between $\ln (\mathrm{k})$ and $1 / \mathrm{T}$, at $80^{\circ} \mathrm{C}, 70^{\circ} \mathrm{C}, 60^{\circ} \mathrm{C}$ and $50^{\circ} \mathrm{C}$. The molar ratio of $n$-butanol:acetic acid was maintained at 1:1, with a catalyst loading of $5 \% \mathrm{w} / \mathrm{w} \mathrm{BuOH}$. The $\mathrm{k}$ value was calculated from the slope of the tangent to the curve at the initial time point, for the second-degree polynomial equation. The values of Ea were: A15, 59.5 $\mathrm{kJ} \cdot \mathrm{mol}^{-1} ; \mathrm{A} 16,32.2 \mathrm{~kJ} \cdot \mathrm{mol}^{-1}$; A36, $67.7 \mathrm{~kJ} \cdot \mathrm{mol}^{-1}$ and Dowex 50WX8, 47.6 $\mathrm{kJ} \cdot \mathrm{mol}^{-1}$. Similar values have been reported for Dowex 50WX8 for the esterification of isobutanol/acetic acid at a molar ratio of $1: 1\left(59.3 \mathrm{~kJ} \cdot \mathrm{mol}^{-1}\right)[6]$.

\subsection{Synthesis of Butyl Acetate Starting from $n$-Butanol and Acetic Anhydride}

Following the same route as for ethyl acetate, and to increase butyl acetate yield, 
$n$-butanol and acetic anhydride were used as the starting reactants, at a molar ratio of 2:1.

$$
\mathrm{CH}_{3}\left(\mathrm{CH}_{2}\right)_{3} \mathrm{OH}+\left(\mathrm{CH}_{3} \mathrm{CO}\right)_{2} \mathrm{O} \rightleftharpoons 2 \mathrm{CH}_{3} \mathrm{COO}\left(\mathrm{CH}_{2}\right)_{3}+\mathrm{H}_{2} \mathrm{O}
$$

The reactions were carried out in the same conditions as for acetic acid: $100^{\circ} \mathrm{C}$, for $4 \mathrm{~h}$, with a catalyst loading of $5 \% \mathrm{w} / \mathrm{w}$ relative to butanol. The changes in $n$-butanol, acetic acid and butyl acetate content were plotted over time (Figure 9).

Equilibrium was reached more rapidly with Dowex 50WX8 $(10 \mathrm{~min})$ than with the other resins. For the macroporous resins A15, A16 and A36, butyl acetate content reached a maximum after $50 \mathrm{~min}$. These results are consistent with those for ethyl acetate production, for which Dowex also had the most rapid kinetics.

Butanol conversion and butyl acetate yield increased by $10 \%$ (from $70 \%$ to $80 \%$ ) when acetic acid was replaced with acetic anhydride (Table 5 and Table 6). Water content was reduced from $30 \%$ to $15 \%$ if acetic anhydride was used as the starting material. This decrease in the water content of the reaction medium displaced the equilibrium to the right, enhancing butyl acetate production.
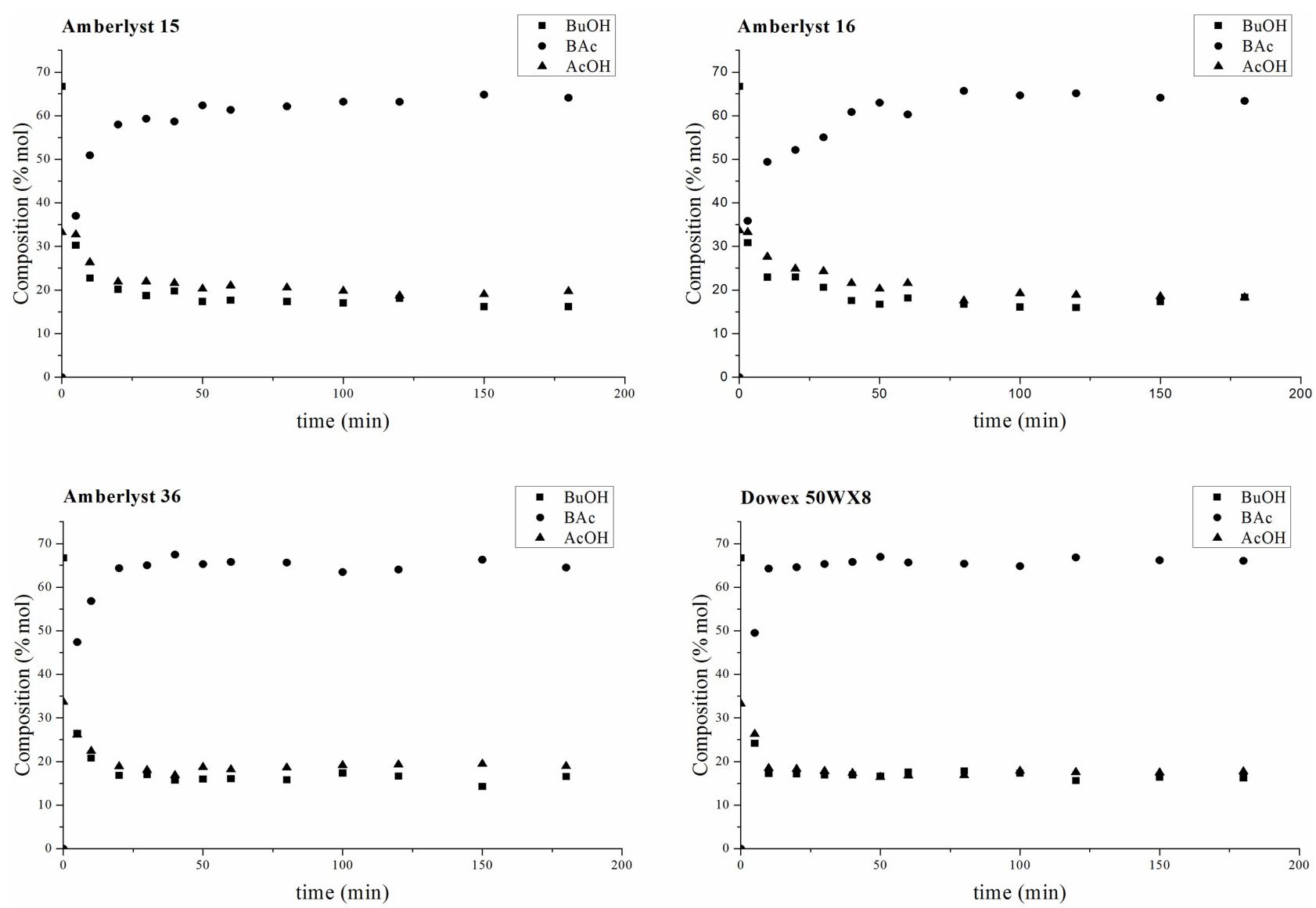

Figure 9. Kinetic study of the synthesis of butyl acetate with $n$-butanol and acetic anhydride (molar ratio: $2: 1$ ) as the starting materials, at $100^{\circ} \mathrm{C}$, in the presence of various ion exchange resins. A15, A16, A36 and D50 (catalyst loading: 5\% w/w relative to butanol weight). 
The best results were obtained with $n$-butanol and acetic anhydride as the starting materials, and Dowex 50WX8 as catalyst.

\subsection{Purification of Butyl Acetate}

In the synthesis of butyl acetate $\left(\mathrm{bp}=126.1^{\circ} \mathrm{C}\right)$ from $n$-butanol $\left(\mathrm{bp}=117.7^{\circ} \mathrm{C}\right)$ and acetic acid $\left(\mathrm{bp}=118.1^{\circ} \mathrm{C}\right)$, three binary azeotropes and one ternary azeotrope are present (Table 7) [1] [48] [55].

For butyl acetate production, an entrainer, such as cyclohexane $\left(80.74^{\circ} \mathrm{C}\right)$, can be used to remove the water produced during the reaction, shifting the equilibrium and increasing both butanol conversion and butyl acetate yield. A Dean Stark apparatus was used (in the reaction from acetic acid) to produce an azeotropic mixture of cyclohexane and water $\left(69.5^{\circ} \mathrm{C}\right)$, and the azeotrope was distilled out of the reaction mixture. The composition of the reaction medium after butyl acetate purification is presented in Table 8 .

Table 6. Comparison of the various ion exchange resins in terms of $n$-butanol conversion and butyl acetate yield, starting from $n$-butanol and acetic anhydride (2:1).

\begin{tabular}{ccccccc}
\hline \multirow{2}{*}{ Ion exchange resins } & Butanol & Yield of BAc & \multicolumn{4}{c}{ Composition of reaction media (\%mol) } \\
\cline { 5 - 7 } & conversion (\%) & $(\%)$ & AcOH & Butanol & BAc & Water $^{\mathrm{a}}$ \\
\hline Amberlyst 15 & 79 & 68 & 17 & 16 & 51 & 17 \\
Amberlyst 16 & 81 & 82 & 16 & 13 & 55 & 16 \\
Amberlyst 36 & 81 & 81 & 14 & 13 & 57 & 16 \\
Dowex 50WX8 200 - 400 & 81 & 83 & 15 & 13 & 57 & 15 \\
\hline
\end{tabular}

Conditions: catalyst loading of $5 \% \mathrm{w} / \mathrm{w}$ relative to $\mathrm{BuOH}, 100^{\circ} \mathrm{C}, 4$ h. a: determined by Karl Fisher titration. Standard deviation: \pm 2

Table 7. Boiling points and molar fractions of the various azeotropes in the butyl acetate system [1] [55] [56].

\begin{tabular}{ccccc}
\hline \multirow{2}{*}{ Azeotropes } & Boiling Point $\left({ }^{\circ} \mathrm{C}\right)$ & \multicolumn{3}{c}{ Molar fractions } \\
\cline { 3 - 5 } & & $\mathrm{BuOH}$ & $\mathrm{BAc}$ & $\mathrm{H}_{2} \mathrm{O}$ \\
\hline $\mathrm{BAc} / \mathrm{H}_{2} \mathrm{O}$ & 90.2 & - & 0.2876 & 0.7134 \\
$\mathrm{BuOH} / \mathrm{BAc}$ & 117.6 & 0.7329 & 0.2671 & - \\
$\mathrm{BuOH} / \mathrm{H}_{2} \mathrm{O}$ & 93.0 & 0.2218 & - & 0.7782 \\
$\mathrm{BuOH} / \mathrm{BAc} / \mathrm{H}_{2} \mathrm{O}$ & 89.4 & 0.0551 & 0.24 & 0.7049
\end{tabular}

Table 8. Composition of the purified butyl acetate obtained by the esterification of butanol and acetic acid in a molar ratio of 1:1.

\begin{tabular}{ccccccc}
\hline $\begin{array}{c}\text { Butanol conversion } \\
(\%)\end{array}$ & $\begin{array}{c}\text { Yield of BAc } \\
(\%)\end{array}$ & $\%$ & \multicolumn{3}{c}{ Composition of reaction media (\%mol) } \\
\cline { 5 - 7 } 99 & \multirow{2}{*}{76} & $\mathrm{~mol}$ & 0.8 & 1.7 & 91.2 & 6.4 \\
\hline
\end{tabular}

Conditions: loading of $5 \%$ w/w Dowex $50 \mathrm{wx} 8 / \mathrm{BuOH}, 100^{\circ} \mathrm{C}, 4$ h. a: determined by Karl Fisher titration. SD: \pm 2 . 
After separation, $n$-butyl acetate was obtained at a purity of $97.4 \%$, with only very small amounts of $n$-butanol and acetic acid that did not react and a small amount of residual water in the mixture. Butanol conversion was increased from $70 \%$ to $99 \%$ by removing water during the reaction but the yield of butyl acetate increased by only $10 \%$ (from $66 \%$ to $76 \%$; Table 6 vs Table 9 ).

A larger increase might have been expected given the improvement in conversion. This relatively low yield after distillation, even with the removal of water, may be due to the double distillation required to remove first water, and then cyclohexane from the medium.

The purity of the butyl acetate obtained was further increased by removing the $1.1 \%$ of water remaining in the medium by adding molecular sieves (3A) in distilled BAc. The water content measured 24 hours later was 0.002\% (Karl Fisher titration).

These studies of the esterification of ethanol or butanol with acetic acid or acetic anhydride show that alcohol conversion and reaction yields are higher if acetic anhydride is used (rather than acetic acid), but the use of this starting material leads to the generation of acetic acid as waste. Thus, to meet the requirements of a circular economy, we decided to use co-product of the reaction in a second esterification, as described below.

\subsection{Coproduction of Ethyl Acetate and $n$-Butyl Acetate}

As previously stated, ethyl acetate is difficult to purify due to the formation of azeotropes with water. Thus, to facilitate the purification of ethyl acetate and to avoid the production of waste when acetic anhydride is used as a reactant (instead of acetic acid), an acetate coproduction strategy was adopted (Scheme 1).

In the first step, the esterification of ethanol and acetic anhydride at an equimolar ratio generates ethyl acetate and acetic acid in the presence of the ion

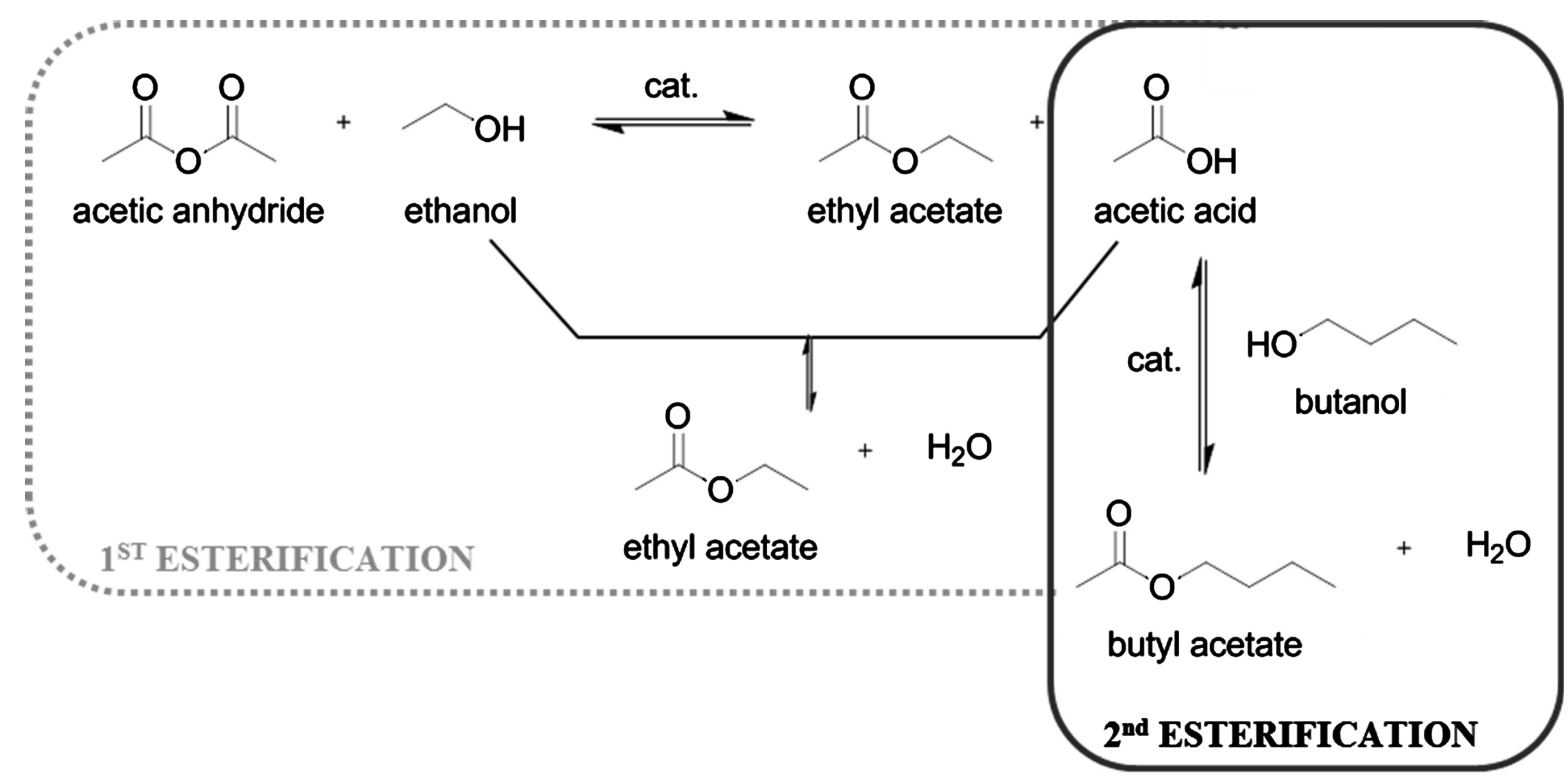

Scheme 1. Coproduction of ethyl acetate and n-butyl acetate. 
exchange resin Dowex 50WX8. Ethyl acetate is easily removed from the reaction mixture by simple distillation.

The second step involves a second esterification reaction between the acetic acid generated in the first reaction and $n$-butanol, which is added to the reactor to produce butyl acetate (Figure 10).

First step: synthesis of ethyl acetate and production of acetic acid

In the synthesis of ethyl acetate from ethanol and acetic anhydride (molar ratio of $1: 1$ ), acetic acid is also produced. The reaction is exothermic and no heating is required (Scheme 2).

As shown in Table 10, water content was reduced from $20 \%$ to $3 \%$ (molar percentage) by using an equimolar ratio of acetic anhydride and ethanol (Table 3 vs Table 9). The stoichiometry of the reaction is consistent with a total absence of water formation, but the presence of this small amount of water can be explained by a slower competitive esterification between the acetic acid generated in the first reaction and the remaining ethanol (Scheme 2). The water generated in this way can also be consumed in the hydrolysis of acetic anhydride to generate acetic acid, with the release of heat. The use of an equimolar ratio of ethanol and acetic anhydride thus gave very high yields of ethyl acetate (98\%) and a high ethanol conversion (99.4\%) at the end of the reaction (Table 9).

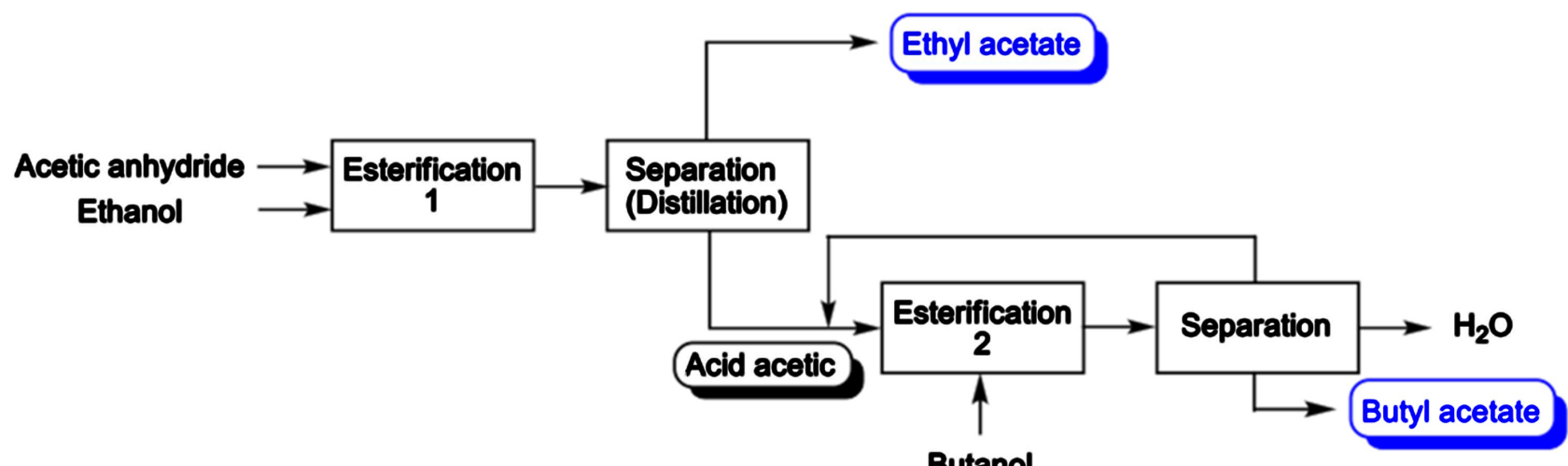

Butanol

Figure 10. Coproduction process for ethyl and butyl acetates
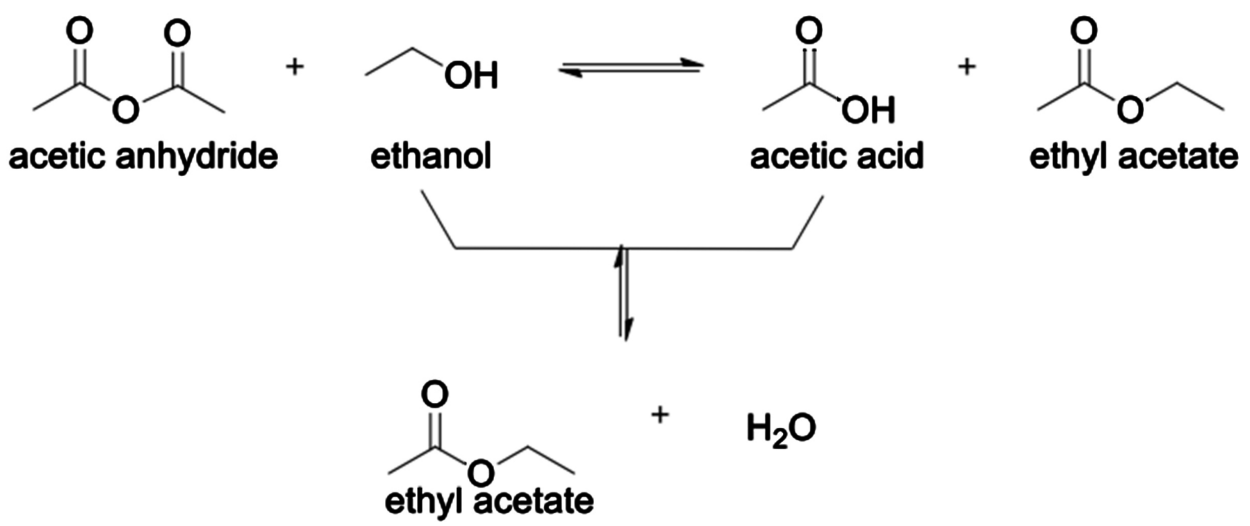

Scheme 2. First step in the coproduction process: synthesis of ethyl acetate from acetic anhydride and ethanol at a molar ratio of $1 / 1$. 
The low water content of the crude mixture facilitates the purification of ethyl acetate. Simple distillation yields a mixture composed principally of ethyl acetate and small amounts of acetic acid and water (Table 9).

\section{Second step: synthesis of $\boldsymbol{n}$-butyl acetate}

From the reaction of ethanol and acetic anhydride at a molar ratio of $1 / 1$, a mixture of acetic acid and ethyl acetate $(77.5 \%$ and $22.5 \% \mathrm{w} / \mathrm{w}$, respectively) remains in the reactor in large amounts, together with the resin, after the removal, by distillation, of most of the ethyl acetate. With a view to preventing waste and recycling this mixture, we propose the addition of $n$-butanol to the reactor for a second esterification reaction to produce $n$-butyl acetate (Scheme 3 ).

The use of the acetic acid/ethyl acetate mixture generated by the first esterification had no influence on the synthesis of butyl acetate. As in the individual synthesis of this molecule, the reaction was carried out with a Dean Stark apparatus and the addition to the mixture of a small amount of cyclohexane to remove water from the reaction. Similar butanol conversion was obtained for both the individual and coproduction syntheses ( $99 \%$ and $94 \%$, respectively). After the purification of butyl acetate, a mixture consisting principally of butyl acetate was obtained $(97.1 \% \mathrm{w} / \mathrm{w})$. Traces of acetic acid, butanol, ethyl acetate and water were detected (Table 10).

Table 9. Composition of the crude reaction mixture and of the distilled ethyl acetate obtained from ethanol and acetic anhydride, at a molar ratio of $1 / 1$, at room temperature for $4 \mathrm{~h}$.

\begin{tabular}{|c|c|c|c|c|c|c|c|}
\hline & \multirow{2}{*}{$\begin{array}{c}\text { Butanol } \\
\text { conversion (\%) }\end{array}$} & \multirow{2}{*}{$\begin{array}{l}\text { Yield of } \\
\text { BAc (\%) }\end{array}$} & \multicolumn{5}{|c|}{ Composition of the reaction medium } \\
\hline & & & $\%$ & $\mathrm{AcOH}$ & $\mathrm{EtOH}$ & EAc & $\mathrm{H}_{2} \mathrm{O}$ \\
\hline \multirow{2}{*}{ At the end of reaction } & \multirow{2}{*}{99.4} & \multirow{2}{*}{98} & mol & 48.4 & 0.3 & 48.5 & 2.8 \\
\hline & & & $\mathrm{w} / \mathrm{w}$ & 40.1 & 0.2 & 59.0 & 0.7 \\
\hline \multirow{2}{*}{ After distillation } & \multirow{2}{*}{100} & \multirow{2}{*}{87} & mol & 9.1 & 0.0 & 85.4 & 5.4 \\
\hline & & & $\mathrm{w} / \mathrm{w}$ & 6.7 & 0.0 & 92.1 & 1.2 \\
\hline
\end{tabular}<smiles>CC(=O)OC(C)=O</smiles>

acetic anhydride
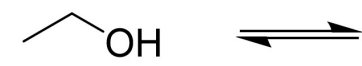

ethanol<smiles>CCOC(C)=O</smiles>

ethyl acetate acetic acid

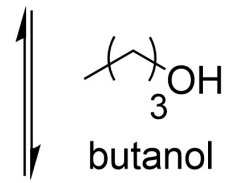<smiles>CC(=O)OC(C)C(C)(C)C(=O)O</smiles>

Scheme 3. Coproduction of ethyl acetate and butyl acetate. 
The proposed novel coproduction process is an interesting way to produce ethyl acetate and butyl acetate, as it generates no waste, and all the reactants are consumed in the reaction, resulting in high yields of the desired esters. Recycling of the resin is also possible.

\subsection{Evaluation of the Environmental Benefit of the Developed Process}

For the studied chemical processes, the evaluation of several indicators related to their environmental impacts and the implementation of green chemistry principles is a way to guide the choice of the greener process among different alternatives. In order to verify that the new coproduction process developed in this work for the syntheses of ethyl and butyl acetates is more eco-friendly than the two independent syntheses, two approaches have been considered: the green metrics evaluation and the Life Cycle Assessment (LCA).

Green metrics provide a quantitative analysis of the efficiency and the environmental performance of chemical reactions and processes [57], which helps to determine which of the chemical synthesis is closest to the definition of green chemistry. They can be related to one or more principles of green chemistry [58]. Table 11 shows the relation between green metrics and the principles of green chemistry that have been considered in the development of the co-production process of acetates using ion exchange resins as catalyst $\left(1^{\text {st }}, 2^{\text {nd }}\right.$, $5^{\text {th }}$ and $9^{\text {th }}$ principles). It is important to highlight that the toxicity ( $3^{\text {rd }}$ principle) and the handling hazards ( $12^{\text {th }}$ principle) were reduced with the developed coproduction pathway, due to the replacement of the sulfuric acid (H314, H318, R35; related to burns risk), used in the current industrial process, by the ion exchange resin Dowex 50WX8 as catalyst. It is noteworthy that the $7^{\text {th }}$ principle

Table 10. Composition of the purified butyl acetate obtained with the coproduction process.

\begin{tabular}{ccccccccc}
\hline \multirow{2}{*}{$\begin{array}{c}\text { Butanol conversion } \\
(\%)\end{array}$} & Yield of & \multicolumn{6}{c}{ Composition of the reaction medium } \\
\cline { 4 - 9 } & BAc (\%) & $\%$ & AcOH & BuOH & EtOH & BAc & EAc & $\mathrm{H}_{2} \mathrm{O}$ \\
\hline 99.4 & mol & 0.2 & 2.9 & 0.0 & 92.7 & 0.2 & 3.9 \\
& & w/w & 0.1 & 1.9 & 0.0 & 97.1 & 0.2 & 0.6 \\
\hline
\end{tabular}

Table 11. Green metrics for the analysis of the co-production process of acetates.

\begin{tabular}{ccc}
\hline Green metrics & Calculation & $\begin{array}{c}\text { Concerning } \\
\text { principles }\end{array}$ \\
\hline Atom economy & $\mathrm{AE}=\frac{\mathrm{M} \text { product }}{\Sigma \mathrm{M} \text { reactants }} \times 100$ & $2^{\text {nd }}$ \\
E-Factor & $\mathrm{E}-$ factor $=\frac{\sum \text { waste }(\mathrm{g})}{\text { product }(\mathrm{g})}$ & $1^{\text {st }}, 5^{\text {th }}, 8^{\text {th }}$ \\
Percentage from renewable sources & $\mathrm{PRS}=\frac{\text { mass of renewable material }}{\text { mass of product }} \times 100$ & $7^{\text {th }}$ \\
\hline
\end{tabular}


related to the use of renewable feedstock was taken into account because ethanol and $n$-butanol can be from bio-based origin. Indeed, nowadays several companies supply bio-ethanol and bio-butanol (for example GreenBiologics, ZeaChem, Abengoa, Shell Global and Pacific ethanol Inc) in the current market.

The atom economy (AE), the environmental (E-factor) and the percentage from renewable sources (PRS) have been calculated for: $i$ ) the individual syntheses starting from acetic anhydride and ethanol (1:1) for the production of ethyl acetate and from acetic acid and butanol (1:1) for the preparation of butyl acetate, and ii) the co-production process of ethyl and butyl acetates.

According to the green metrics gathered in the Table 12, the developed co-production pathway resulted in a more efficient process compared to the individual syntheses. The $\mathrm{AE}$ was higher with the co-production process thanks to the recycling of the acetic acid produced in the first esterification as it was used as reagent in the second one for the synthesis of butyl acetate. As it was expected, the E-factor of the co-production was lower (0.31) than the individual syntheses thanks to the smaller amount of generated waste. Furthermore, regarding the percentage of renewable sources, same values were calculated when bio-based ethanol and $n$-butanol were used in the individual syntheses and in the co-production process (Table 12).

As these green metrics do not show the environmental contribution of the whole process and in particular they do not take into account any energy consumption, the life cycle assessments of both pathways of production of ethyl and butyl acetates (Sc.1: individual syntheses and Sc.2: the co-production) have been compared [59]. The LCA analyses have shown that the co-production process generates lesser impacts on the environment than the individual syntheses of ethyl and butyl acetates (Figure 11). These results can be explained by two principal factors: 1) the reduction of the amount of waste thanks to the use of the acetic acid (co-product for the first esterification) in the second reaction, and 2) the recycling of the ion exchange resin in the second esterification (without regeneration treatment)

\section{Conclusions}

We propose here a sustainable and innovative process for the coproduction of ethyl acetate and butyl acetate that respects the principles of green chemistry. Ion exchange resins were used to replace homogeneous catalysts, to reduce waste

Table 12. Green metrics for the classical individual synthesis and the co-production process developed in this work.

\begin{tabular}{cccc}
\hline Process & $\%$ AE & E-factor & $\%$ PRS \\
\hline Ethyl and butyl acetates through individual synthesis & 72.4 & 0.68 & $57.90^{\mathrm{a}}$ \\
Ethyl and butyl acetates through coproduction process & 91.9 & 0.31 & $57.90^{\mathrm{a}}$ \\
\hline
\end{tabular}

aPercentage from renewable sources calculated considering that ethanol and butanol are from bio-based feedstock. 


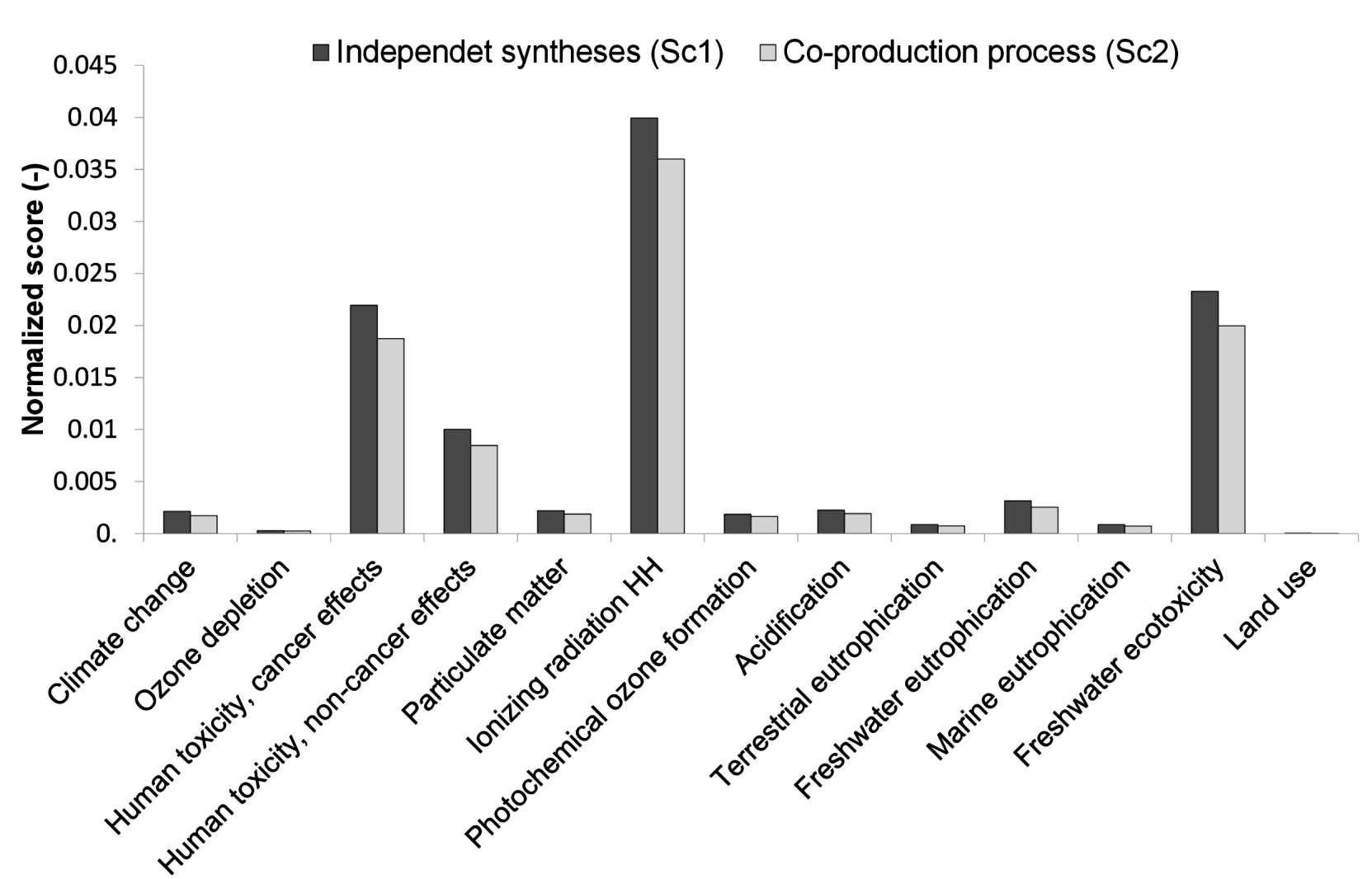

Figure 11. Comparison between the independent syntheses and the co-production process of acetates. Normalization of the impacts by a derivative of the ILCD 20111.05 method.

generation. The gel-type resin Dowex 50WX8 outperformed the other macroporous resins tested, for the production of ethyl and butyl acetates.

The first step in the coproduction process was the synthesis of EAc from ethanol and acetic anhydride at a 1:1 molar ratio. This reaction produces EAc and acetic acid and decreases water production, thereby facilitating the purification of ethyl acetate. In the second step, the acetic acid generated by the first reaction is used as a starting material for a second esterification to produce butyl acetate.

The environmental benefit for the coproduction process respect to the independent syntheses of ethyl and butyl acetates was demonstrated through the calculation of the green metrics and the LCA analyses. This coproduction process has the advantages of preventing waste, facilitating the purification of the desired acetates and reusing the co-products and the catalyst.

\section{Acknowledgements}

This work was supported by the European Union's Seventh Framework Program for research, technological development and demonstration (FP7/2007-2013) [Grant Agreement No. 605215]. Nydia Guzman acknowledges CONACyT for providing funding through $\mathrm{PhD}$ scholarship no. 383910.

\section{References}

[1] Le Berre, C., Serp, P., Kalck, P. and Torrence, G.P. (2014) Acetic Acid. In: Ull- 
mann's Encyclopedia of Industrial Chemistry, Wiley-VCH Verlag GmbH \& Co. KgaA, Weinheim, 1-34. https://doi.org/10.1002/14356007.a01_045.pub3

[2] Rönnback, R., Salmi, T., Vuori, A., Haario, H., Lehtonen, J., Sundqvist, A. and Tirronen, E. (1997) Development of a Kinetic Model for the Esterification of Acetic acid with Methanol in the Presence of a Homogeneous Acid Catalyst. Chemical Engineering Science, 52, 3369-3381. https://doi.org/10.1016/S0009-2509(97)00139-5

[3] Kantam, M.L., Bhaskar, V. and Choudary, B.M. (2002) Direct Condensation of Carboxylic Acids with Alcohols: The Atom Economic Protocol Catalysed by $\mathrm{Fe}^{3+}$-Montmorillonite. Catalysis Letters, 78, 185-188.

https://doi.org/10.1023/A:1014993809745

[4] Liu, Y., Lotero, E. and Goodwin, J. (2006) A Comparison of the Esterification of Acetic Acid with Methanol Using Heterogeneous versus Homogeneous Acid Catalysis. Journal of Catalysis, 242, 278-286. https://doi.org/10.1016/j.jcat.2006.05.026

[5] Cheremisinoff, N. (2003) Industrial Solvents Handbook. 2nd Edition, Marcel Dekker, Inc., New York. https://doi.org/10.1201/9780203911334

[6] Izci, A. and Bodur, F. (2007) Liquid-Phase Esterification of Acetic Acid with Isobutanol Catalyzed by Ion-Exchange Resins. Reactive and Functional Polymers, 67, 1458-1464. https://doi.org/10.1016/j.reactfunctpolym.2007.07.019

[7] Gangadwala, J., Mankar, S., Mahajani, S., Kienle, A. and Stein, E. (2003) Esterification of Acetic Acid with Butanol in the Presence of Ion-Exchange Resins as Catalysts. Industrial \& Engineering Chemistry Research, 42, 2146-2155. https://doi.org/10.1021/ie0204989

[8] Teo, H. and Saha, B. (2004) Heterogeneous Catalysed Esterification of Acetic Acid with Isoamyl Alcohol: Kinetic Studies. Journal of Catalysis, 228, 174-182. https://doi.org/10.1016/j.jcat.2004.08.018

[9] Karakus, S., Sert, E., Buluklu, D. and Atalay, F.S. (2014) Liquid Phase Esterification of Acrylic Acid with Isobutyl Alcohol Catalyzed by Different Cation Exchange Resins. Industrial \& Engineering Chemistry Research, 53, 4192-4198. https://doi.org/10.1021/ie4037593

[10] Ali, S.H. and Merchant, S.Q. (2006) Kinetics of the Esterification of Acetic Acid with 2-Propanol: Impact of Different Acidic Cation Exchange Resins on Reaction Mechanism. International Journal of Chemical Kinetics, 38, 593-612. https://doi.org/10.1002/kin.20193

[11] Anasthas, H.M. and Gaikar, V.G. (2001) Adsorption of Acetic Acid on Ion-Exchange Resins in Non-Aqueous Conditions. Reactive and Functional Polymers, 47, 23-35. https://doi.org/10.1016/S1381-5148(00)00066-3

[12] Jagadeesh, R., Junge, H., Pohl, M., Radnik, J., Bru, A. and Beller, M. (2013) Selective Oxidation of Alcohols to Esters Using Heterogeneous $\mathrm{CO}_{3} \mathrm{O}_{4}-\mathrm{NaC}$ Catalysts under Mild Conditions. Journal of the American Chemical Society, 135, 10776-10782. https://doi.org/10.1021/ja403615c

[13] Nachod, F.C. and Schubert, J. (1956) Ion Exchange Technology. Academic Press Inc., New York.

[14] Harmer, M.A. and Sun, Q. (2001) Solid Acid Catalysis Using Ion-Exchange Resins. Applied Catalysis A: General, 221, 45-62. https://doi.org/10.1016/S0926-860X(01)00794-3

[15] Altiokka, M.R. and Çitak, A. (2003) Kinetics Study of Esterification of Acetic Acid with Isobutanol in the Presence of Amberlite Catalyst. Applied Catalysis A: General, 239, 141-148. https://doi.org/10.1016/S0926-860X(02)00381-2 
[16] Barbaro, P. and Liguori, F. (2009) Ion Exchange Resins: Catalyst Recovery and Recycle. Chemical Reviews, 109, 515-529. https://doi.org/10.1021/cr800404j

[17] Alexandratos, S.D. (2009) Ion-Exchange Resins: A Retrospective from Industrial and Engineering Chemistry Research. Industrial \& Engineering Chemistry Research, 48, 388-398. https://doi.org/10.1021/ie801242v

[18] Jagadeesh Babu, P.E., Sandesh, K. and Saidutta, M.B. (2011) Kinetics of Esterification of Acetic Acid with Methanol in the Presence of Ion Exchange Resin Catalyst. Industrial \& Engineering Chemistry Research, 50, 7155-7160. https://doi.org/10.1021/ie101755r

[19] Chakrabarti, A. and Sharma, M.M. (1993) Cationic Ion Exchange Resins as Catalyst. Reactive Polymers, 20, 1-45. https://doi.org/10.1016/0923-1137(93)90064-M

[20] Peters, T.A., Benes, N.E., Holmen, A. and Keurentjes, J.T.F. (2006) Comparison of Commercial Solid Acid Catalysts for the Esterification of Acetic Acid with Butanol. Applied Catalysis A: General, 297, 182-188. https://doi.org/10.1016/j.apcata.2005.09.006

[21] Wang, N., Wang, R., Shi, X. and Zou, G. (2012) Ion-Exchange-Resin-Catalyzed Adamantylation of Phenol Derivatives with Adamantanols: Developing a Clean Process for Synthesis of 2-(1-adamantyl)-4-bromophenol, a Key Intermediate of Adapalene. Beilstein Journal of Organic Chemistry, 8, 227-233. https://doi.org/10.3762/bjoc.8.23

[22] Berg, L. and Ratanapupech, P. (1982) Separation of Ethyl Acetate from Ethanol and Water by Extractive Distillation. US Patent No. 4379028.

[23] Berg, L. and Ratanapupech, P. (1984) Process for the Separation of Ethyl Acetate from Ethanol and Water by Extractive Distillation. US Patent No. 4569726A.

[24] Zhu, Z., Ri, Y., Jia, H., Li, X., Wang, Y. and Wang, Y. (2017) Process Evaluation on the Separation of Ethyl Acetate and Ethanol Using Extractive Distillation with Ionic Liquid. Separation and Purification Technology, 181, 44-52. https://doi.org/10.1016/j.seppur.2017.03.011

[25] Andreatta, A.E., Charnley, M.P. and Brennecke, J.F. (2015) Using Ionic Liquids to Break the Ethanol-Ethyl Acetate Azeotrope. ACS Sustainable Chemistry \& Engineering, 3, 3435-3444. https://doi.org/10.1021/acssuschemeng.5b01175

[26] William, C.S., Fawcett, C.R., Sharif, M., Marshall Tuck, M.W., Watson, D.J. and Wood, M.A. (1999) Purification of Ethyl Acetate from Mixtures Comprising Ethanol and Water by Pressure Swing Distillation. Patent No. EP1117629B1.

[27] Zhang, Q., Liu, M., Li, C. and Zeng, A. (2017) Heat-Integrated Pressure-Swing Distillation Process for Separating the Minimum-Boiling Azeotrope Ethyl-Acetate and Ethanol. Separation and Purification Technology, 189, 310-334. https://doi.org/10.1016/j.seppur.2017.08.016

[28] Yang, J., Zhou, M., Wang, Y., Zhang, X. and Wu, G. (2017) Simulation of Pressure-Swing Distillation for Separation of Ethyl Acetate-Ethanol-Water. IOP Conference Series: Materials Science and Engineering, 274, Article ID: 012026.

[29] Lee, H.-Y., Huang, H.-P. and Chien, I.-L. (2007) Control of Reactive Distillation Process for Production of Ethyl Acetate. Journal of Process Control, 17, 363-377. https://doi.org/10.1016/j.jprocont.2006.10.002

[30] Fernandez, M.F., Barroso, B., Meyer, X.M., Meyer, M., Le Lann, M.-V., Le Roux, G.C. and Brehelin, M. (2013) Experiments and Dynamic Modeling of a Reactive Distillation Column for the Production of Ethyl Acetate by Considering the Heterogeneous Catalyst Pilot Complexities. Chemical Engineering Research and Design, 91, 2309-2322. https://doi.org/10.1016/j.cherd.2013.05.013 
[31] Lv, B., Liu, G., Dong, X., Wei, W. and Jin, W. (2012) Novel Reactive Distillation-Pervaporation Coupled Process for Ethyl Acetate Production with Water Removal from Reboiler and Acetic Acid Recycle. Industrial and Engineering Chemistry Research, 51, 8079-8086. https://doi.org/10.1021/ie3004072

[32] Lai, I.-K., Liu, Y.-C., Yu, C.-C., Lee, M.-J. and Huang, H.-P. (2008) Production of High-Purity Ethyl Acetate Using Reactive Distillation: Experimental and Start-Up Procedure. Chemical Engineering and Processing. Process Intensification, 47, 1831-1843. https://doi.org/10.1016/j.cep.2007.10.008

[33] Santaella, M.A., Orjuela, A. and Narváez, P.C. (2015) Comparison of Different Reactive Distillation Schemes for Ethyl Acetate Production Using Sustainability Indicators. Chemical Engineering and Processing: Process Intensification, 96, 1-13. https://doi.org/10.1016/j.cep.2015.07.027

[34] Tian, H., Zheng, H., Huang, Z., Qiu, T. and Wu, Y. (2012) Novel Procedure for Coproduction of Ethyl Acetate and n-Butyl Acetate by Reactive Distillation. Industrial \& Engineering Chemistry Research, 51, 5535-5541. https://doi.org/10.1021/ie202154x

[35] Gadewar, S.B. (2013) Ethyl Acetate Production. US Patent No. 8562921B2.

[36] Tian, H., Zhao, S., Zheng, H. and Huang, Z. (2015) Optimization of Coproduction of Ethyl Acetate and n-Butyl Acetate by Reactive Distillation. Chinese Journal of Chemical Engineering, 23, 667-674. https://doi.org/10.1016/j.cjche.2014.12.007

[37] ISO 14040 (2006) Management Environnemental-Analyse du cycle de viePrincipes et cadre.

[38] International Organization for Standardization (2006) ISO 14044: Environmental Management. Life Cycle Assessment. Requirements and Guidelines.

[39] Lee, M.-J., Wu, H.-T. and Lin, H. (2000) Kinetics of Catalytic Esterification of Acetic Acid and Amyl Alcohol over Dowex. Industrial \& Engineering Chemistry Research, 39, 4094-4099. https://doi.org/10.1021/ie0000764

[40] Toteja, R.S.D., Jangida, B.L., Sundaresan, M. and Venkataramani, B. (1997) Water Sorption Isotherms and Cation Hydration in Dowex 50W and Amberlyst ${ }^{-1} 5$ Ion Exchange Resins. Langmuir, 13, 2980-2982. https://doi.org/10.1021/la9607114

[41] Beula, C. and Sai, P.S.T. (2015) Kinetics of Esterification of Acetic Acid and Ethanol with a Homogeneous Acid Catalyst. Indian Chemical Engineer, 57, 177-196. https://doi.org/10.1080/00194506.2014.975761

[42] Atalay, F.S. (2008) Kinetics of the Esterification Reaction between Ethanol and Acetic Acid. Developments in Chemical Engineering and Mineral Processing, 2, 181-184. https://doi.org/10.1002/apj.5500020210

[43] Xu, Z.P. and Chuang, K.T. (1996) Kinetics of Acetic Acid Esterification over Ion Exchange Catalysts. The Canadian Journal of Chemical Engineering, 74, 493-500. https://doi.org/10.1002/cjce.5450740409

[44] Kolena, J., Lederer, J., Morávek, P., Hanika, J., Smejkal, Q. and Skála, D. (2004) Method of Producing Ethyl Acetate and an Equipment for Carrying out This Method. US Patent No. 6693213.

[45] Casson, V., Lister, D.G., Milazzo, M.F. and Maschio, G. (2012) Comparison of Criteria for Prediction of Runaway Reactions in the Sulphuric Acid Catalyzed Esterification of Acetic Anhydride and Methanol. Journal of Loss Prevention in the Process Industries, 25, 209-217. https://doi.org/10.1016/j.jlp.2011.09.002

[46] Duh, Y.-S., Hsu, C.-C., Kao, C.-S. and Yu, S.W. (1996) Applications of Reaction Calorimetry in Reaction Kinetics and Thermal Hazard Evaluation. Thermochimica Acta, 285, 67-79. https://doi.org/10.1016/0040-6031(96)02899-7 
[47] Horsley, L.H. (1973) Azeotropic Data-III. Vol. 116, American Chemical Society, Washington DC. https://doi.org/10.1021/ba-1973-0116

[48] Gmehling, J., Menke, J., Krafczyk, J., Fischer, K., Fontaine, J.-C. and Kehiaian, H.V. (2005) Fluid Properties. In: Handbook of Chemistry and Physics, 92th Edition, CRC Press, Boca Raton, 6-210.

[49] Singh, D., Gupta, R.K. and Kumar, V. (2014) Experimental Studies of Industrial-Scale Reactive Distillation Finishing Column Producing Ethyl Acetate. Industrial \& Engineering Chemistry Research, 53, 10448-10456. https://doi.org/10.1021/ie404443g

[50] Brandt, S., Horstmann, S., Steinigeweg, S. and Gmehling, J. (2014) Phase Equilibria and Excess Properties for Binary Systems in Reactive Distillation Processes. Part II. Ethyl Acetate Synthesis. Fluid Phase Equilibria, 376, 48-54.

https://doi.org/10.1016/j.fluid.2014.05.031

[51] Van Baelen, D., Van der Bruggen, B., Van den Dungen, K., Degreve, J. and Vandecasteele, C. (2005) Pervaporation of Water-Alcohol Mixtures and Acetic Acid-Water Mixtures. Chemical Engineering Science, 60, 1583-1590. https://doi.org/10.1016/j.ces.2004.10.030

[52] Dutta, B.K. and Sikdar, S.K. (1991) Separation of Azeotropic Organic Liquid Mixtures by Pervaporation. AIChE Journal, 37, 581-588. https://doi.org/10.1002/aic.690370411

[53] Lipnizki, F., Field, R.W. and Ten, P.-K. (1999) Pervaporation-Based Hybrid Process: A Review of Process Design, Applications and Economics. Journal of Membrane Science, 153, 183-210. https://doi.org/10.1016/S0376-7388(98)00253-1

[54] Buchaly, C. and Kreis, P. (2007) Hybrid Separation Processes-Combination of Reactive Distillation with Membrane Separation. Chemical Engineering and Processing. Process Intensification, 46, 790-799. https://doi.org/10.1016/j.cep.2007.05.023

[55] Berg, L. and Yeh, A.-I. (1984) Separation of n-Butyl Acetate from n-Butanol by Extractive Distillation. US Patent No. 4507176.

[56] Sert, E. and Atalay, F.S. (2011) Chemical and Biochemical Engineering Quarterly. Chemical and Biochemical Engineering Quarterly, 25, 221-227.

[57] Anastas, P.T. and Zimmerman, J.B. (2013) Innovations in Green Chemistry and Green Engineering: Selected Entries from the Encyclopedia of Sustainability Science and Technology. Springer, Berlin. https://doi.org/10.1007/978-1-4614-5817-3

[58] Anastas, P.T. and Warner, J.C. (1998) Green Chemistry: Theory and Practice. Oxford University Press, New York.

[59] Bories, C., Guzman Barrera, N.I., Peydecastaing, J., Etxeberria, I., Vedrenne, E., Vaca-Garcia, C., Thiebaud-Roux, S. and Sablayrolles, C. (2018) LCA Case Study: Comparison between Independent and Coproduction Pathways for the Production of Ethyl and n-Butyl Acetates. The International Journal of Life Cycle Assessment, 23, 251-266. https://doi.org/10.1007/s11367-017-1317-8 